Document downloaded from:

http://hdl.handle.net/10251/60065

This paper must be cited as:

Galindo, J.; Tiseira Izaguirre, AO.; Fajardo, P.; García-Cuevas González, LM. (2014). Development and validation of a radial variable geometry turbine model for transient pulsating flow applications. Energy Conversion and Management. 85:190-203. doi:10.1016/j.enconman.2014.05.072.

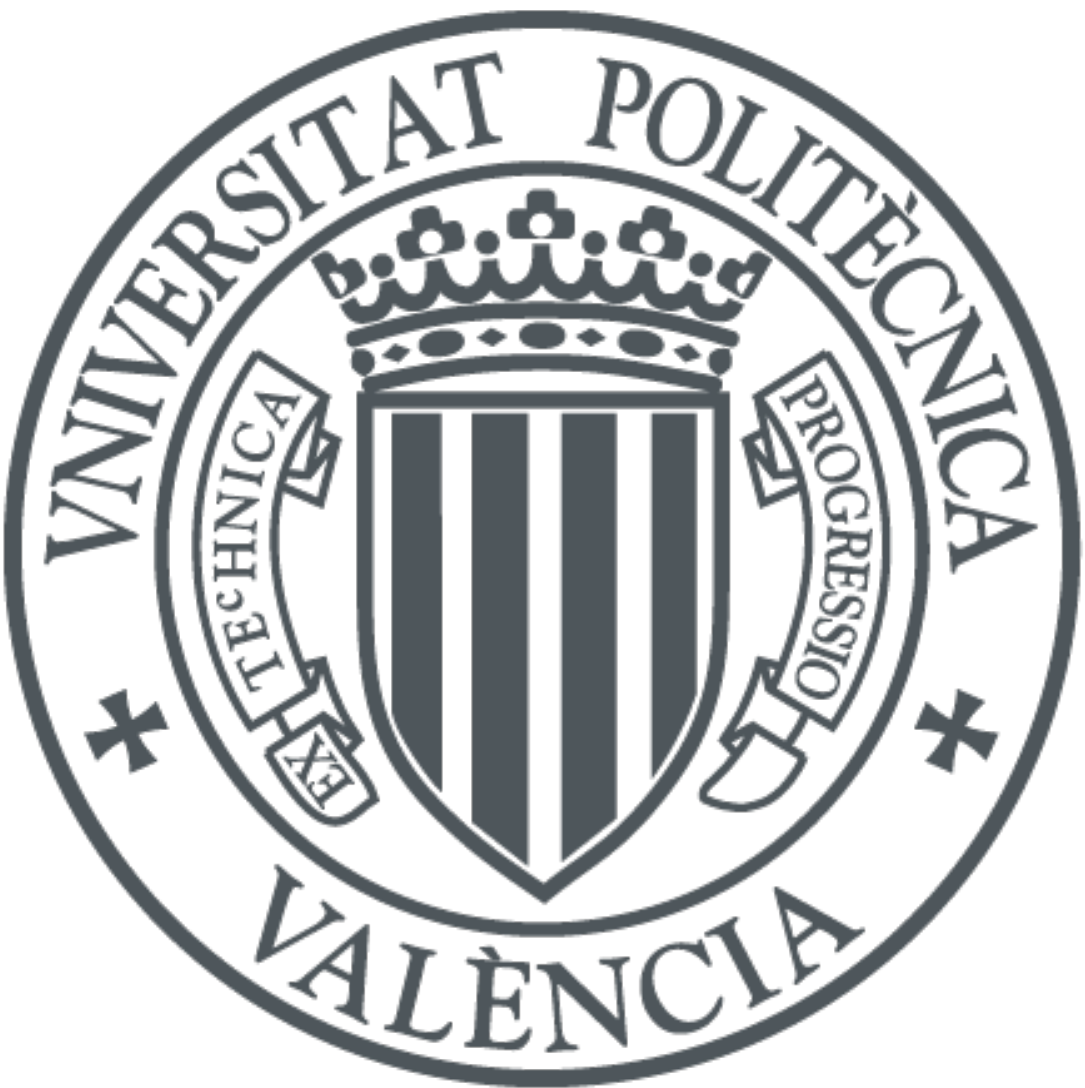

The final publication is available at

http://dx.doi.org/10.1016/j.enconman.2014.05.072

Copyright Elsevier

Additional Information 


\title{
Development and Validation of a Radial Variable Geometry Turbine Model for Transient Pulsating Flow Applications
}

\author{
J. Galindo ${ }^{\mathrm{a}}$, A. Tiseira ${ }^{\mathrm{a}}$, P. Fajardo ${ }^{\mathrm{b}}$, L.M. García-Cuevas ${ }^{\mathrm{a}, *}$ \\ ${ }^{a}$ CMT-Motores Térmicos, Universitat Politècnica de València, Valencia 46022, Spain. \\ ${ }^{b}$ Bioingeniería e Ingeniería Aeroespacial, Universidad Carlos III de Madrid, Leganés 28911, Spain.
}

\begin{abstract}
This paper presents the development and validation of a one-dimensional radial turbine model able to be used in automotive turbocharger simulations. The model has been validated using results from a numerical 3D CFD simulation of stationary and pulsating flow in a variable geometry radial turbine. As the CFD analysis showed, the main non-quasi-steady behavior of the turbine is due to the volute geometry, so special care was taken in order to properly model it while maintaining low computational costs. The flow in the volute has been decomposed in its radial and azimuthal direction. The azimuthal flow corresponds to the flow moving along the volute, while the radial flow is computed by coupling its flow with a stator model. Although the stator caused fewer accumulation effects than the volute, a small accumulation model has been used for it, which also allows to compute the evolution of the flow inside the turbine with lower costs. The flow in the moving rotor can be considered quasi-steady, so a zero-dimensional model for the rotor has been developed. Several losses models where implemented for both the stator and the rotor. The results show good agreement with the CFD computations.
\end{abstract}

Keywords: Turbocharger, Model, Mean-line model, Radial turbine simulation, Pulsating flow

\section{Introduction}

Turbocharged engines date back to the 1920's, starting with aircraft engines and big ship engines, and it is a well-established technology. During the last two decades, tighter emission regulations and rising fuel costs have been driving engine manufacturers to use turbochargers in an ever-increasing number. This has led to the parallel development of fast zero-dimensional and one-dimensional computational codes for engine simulation that allows manufacturers to improve their designs. The usual assumption while computing turbochargers attached to one-dimensional gas dynamic codes is to simulate them in a quasi-steady manner using gas-stand measured maps.

Quasi-steady simulations based in turbine maps present three main drawbacks: no extrapolation capabilities, heat transfer and mechanical losses coupling with the measured performance and efficiency and result discrepancies when simulating pulsating flow. Some authors have devoted great efforts in the last decade to the research and development of codes that not only simulates the turbocharger in a quasi-steady manner, but also extrapolate turbine maps [1]. Payri et al. [2] presented a physically-based methodology to extrapolate turbine maps. Heat transfer properties of turbochargers can be determined and used to compute the behaviour of the turbocharger under arbitrary temperature conditions $[3,4,5,6]$. Mechanical losses models show also an important role in the prediction of turbocharger performance under both steady-state and pulsating

\footnotetext{
*Corresponding author. Tel: +34963877650; fax: +34963877659

Email address: luiga12@mot.upv.es (L.M. García-Cuevas)

URL: www. cmt.upv.es (L.M. García-Cuevas)
}

flow conditions $[7,8]$. To address the main effects in turbine performance under unsteady flow, both experimental and numerical tests must be carried out. The general opinion is that the impeller can be treated as quasi-stationary, whereas almost all the accumulation and wave effects are located in the volute [9, 10]. Hakeem et al. [11] tested the influence of the volute geometry in turbine performance under steady and unsteady conditions, showing differences in the observed behaviour between steady-state and unsteady tests. Although done for a radial compressor, Abdelmadjid et al. [12] showed big effects in compressor performance due to variations in its volute geometry using CFD simulations.

Different authors cope with radial turbine unsteadiness in different ways. One of the typical assumptions can be seen in the work from Chen et al. [13], where the volute is simulated using a one-dimensional tapered pipe of a certain length, while solving the rotor using a quasi-steady model. More rencetly, Chiong et al. [14] predict single entry turbine performance with a one-dimensional model coupled with a mean-line model of the rotor. In their model, the volute is approximated by an straight duct with a length of half the real volute length and the rotor is also modelled using an straight pipe, with two pressure drop boundaries. The results from the one-dimensional calculation are then used with a mean-line model of the rotor to compute its efficiency. Macek et al. [15] compute the whole turbine using one-dimensional sub-models, adding appropriate source terms in the rotor to take into account its rotational movement, but uses an equivalent, half-length one-dimensional volute duct. A comprehensive overview of the different methods developed up to the year 2010 can be found in [16]. 
The research team from which the authors form part has a long history of one-dimensional ICE code development dating back to 1984, going up to the latest developments in heat transfer and mechanical losses modelling in turbochargers ${ }^{1}[5,7]$. The prior turbine model developed by this research team, while satisfactorily used in ICE simulations and capable of predicting the turbine unsteady behaviour, has some quirks for map extrapolation and high-frequency response. This has led to the development of a new model more able at transient and highamplitude pulsating flow applications, which has proven to give better mass flow rate and turbine power output oscillation amplitude predictions during high frequency and high amplitude simulations.

This work is divided as follows: first, a basic description of the model is shown; second, the model is validated against CFD results; then, the main conclusions are presented; finally, the model is described in detail in an appendix.

\section{Model description}

The objective of the model described in the present work is to properly simulate the behaviour of a radial automotive turbine under unsteady operation with a small computational cost. The research group from which the authors of this paper form part has satisfactorily developed a prior adiabatic automotive turbine model, as can be seen in the work from Serrano et al. [17]. The model is corrected due to heat losses with a nodal model as shown in Olmeda et al. [5]. Although this model shows good results in realistic test cases, as can be seen in [18], its response starts to degrade at high frequencies and its extrapolation capabilities are limited when a low number of points from the turbine map is available. In order to improve its response at high frequencies, an improved volute model is needed; to improve its extrapolation capabilities, a better model of the stator and rotor is required. In order to not penalise the simulation time when connected to a full engine model, its computational speed is also critical: it is expected that one-dimensional engine models will be used in the near future for hardware-in-theloop simulations, which are nowadays done with quasi-steady models as seen in the work from Du et al. [19]. A model that can compute the entropy generation of the different elements of the turbine is desirable and should allow to develop methods to minimise those inefficiencies, such as in the work from Cheng and Liang [20].

The model described in this paper has been fed with data from a CFD campaign made by the authors' research group, whose results where published in [10]. In that work, an automotive radial turbine was simulated with straight ducts attached to its inlet and outlet, behaving similarly to a turbine in a turbocharger gas stand. The different sections considered in the computational domain are described in Table 1:

The simulated boundary conditions were of constant pressure at the domain outlet and sinusoidal in total pressure with

\footnotetext{
${ }^{1}$ The code developed by this team is available under a copyleft license at http: //www. openwam. org for peer-review by other researchers
}

\begin{tabular}{ll}
\hline Section number & Description \\
\hline 0 & Domain inlet \\
1 & Turbine inlet \\
2 & Volute outlet - stator inlet \\
3 & Stator outlet - rotor inlet \\
4 & Rotor outlet \\
5 & Turbine outlet \\
6 & Domain outlet \\
\hline
\end{tabular}

Table 1: Situation of the different sections considered in the computational domain.

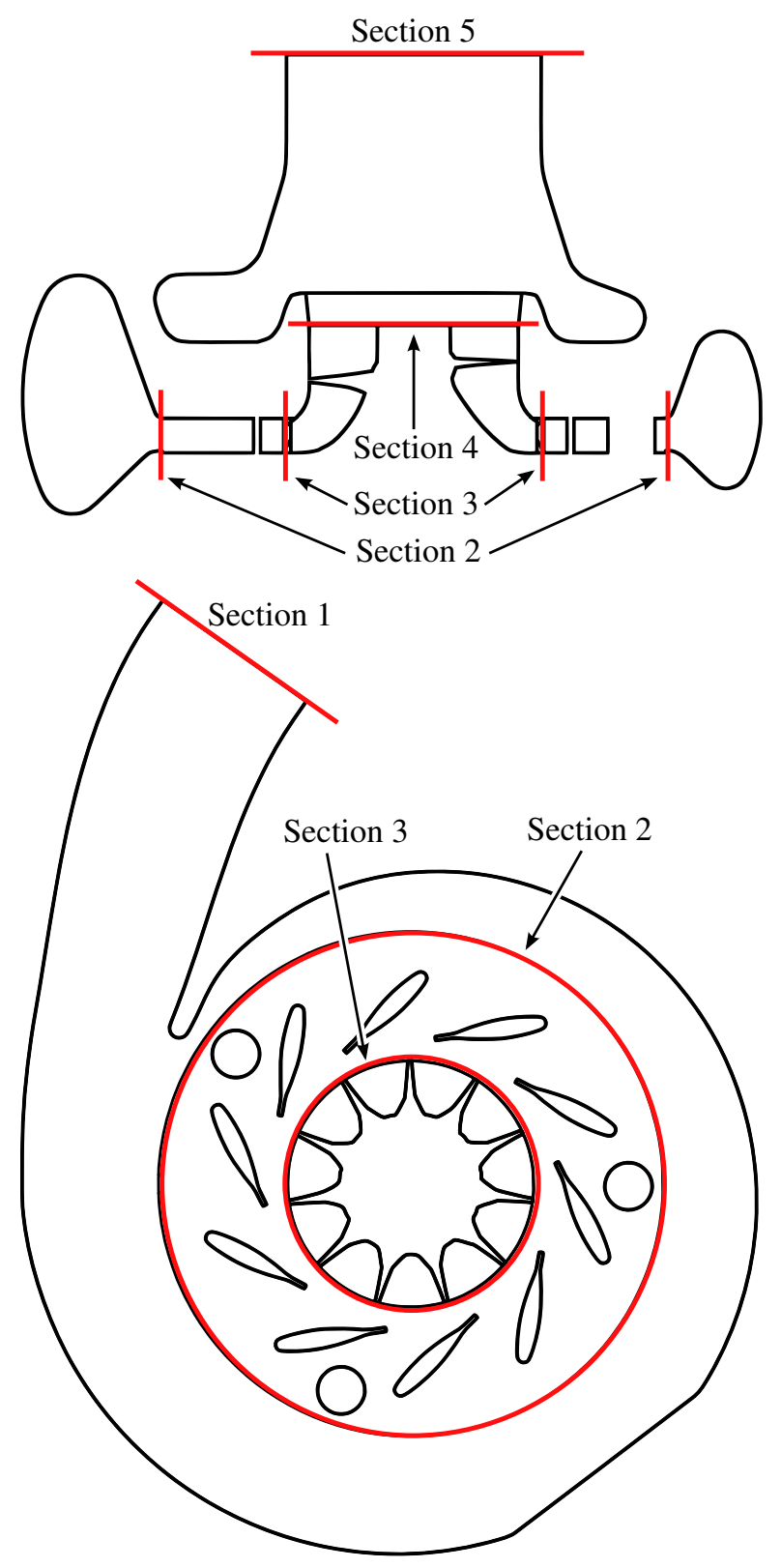

Figure 1: CFD domain with highlighted sections. 
isentropic evolution of total temperature at the domain inlet. Several pressure oscillation frequencies were used. The results from these simulations were used to calibrate and validate the model developed in the present work. A scheme of the CFD domain is shown in Figure 1, where some of the sections where the flow variables were monitored are drawn. The sections are described in Table 1

The model is fully presented in Appendix A, and a shallow explanation is exposed in the following paragraphs. The simplified model consists of the following parts:

- One-dimensional ducts: the small turbine inlet duct before the volute tongue, the turbine outlet duct and the volume of the stator (where small accumulation effects may appear).

- One-dimensional duct with source terms generated by radial flow: the volute.

- Constant stagnation enthalpy elements: the stator nozzles.

- Constant rothalpy element: the rotor.

The section numbering used in Table 2 is maintained for consistency purposes, but other boundaries between elements appear, such as the connection between the turbine inlet duct and the volute or the recirculating connection in the volute tongue.

All the one-dimensional elements are solved using a highresolution (see [21]), Riemann-solver (such as in the work from Einfeld [22] or Toro et al. [23]) based finite-volume method:

$$
\begin{aligned}
\frac{\mathrm{d} \overline{\boldsymbol{w}}_{\boldsymbol{i}}}{\mathrm{d} t} & =\frac{\mathrm{d}}{\mathrm{d} t} \cdot\left(\begin{array}{c}
\rho \\
\rho \cdot u \\
\rho \cdot c_{v} \cdot T+\rho \cdot u^{2} / 2
\end{array}\right)_{i} \\
& =\frac{\left(A_{i-1, i} \cdot \boldsymbol{F}_{i-1, i}-A_{i, i+1} \cdot \boldsymbol{F}_{i, i+1}+\boldsymbol{C}_{i}\right)}{V_{i}}
\end{aligned}
$$

where the density $\rho_{i}$, the temperature $T_{i}$ and the speed $u_{i}$ are the mean values at the cell $i, V_{i}$ is the cell volume, $A_{i-1, i}$ and the surface that is in contact between cells $i-1$ and $i . \boldsymbol{F}_{i, i+1}$ is the flow vector between cells $i-1$ and $i$ and is computed using an approximate Riemann solver and using limited extrapolated values for the state vector at both sides of the boundary in order to obtain second-order total-variation-diminishing behaviour. The sources vector $\boldsymbol{C}_{i}$ contains the terms that affect the cell globally and not only on the inter-cell interfaces, such as heat flow.

The non-uniformity of the flow in the volute outlet during the pulse transmission cannot be captured with such a 1D model as those of Serrano et al. [17]. This could be done with a quasi2D model of the volute, in which the tangential and radial components are calculated by imposing conservation of angular momentum, similar to the work presented by Bozza et al. [24] for a centrifugal compressor. In the special case of the volute, where a lateral window permits the air to flow outside of it, the flow mainly moves along the azimuthal coordinate except near the window, where an important radial component appears. This radial component generates source terms for each volute computational cell. The volute is simulated as a tapered duct with one end connected to the turbine inlet one-dimensional duct, another end connected again to the first one so some recirculation is possible around the volute tongue, and source terms for each cell that are computed using the stator results:

$$
\boldsymbol{C}_{i}=\left.\frac{\mathrm{d} m}{\mathrm{~d} t}\right|_{i} \cdot\left(\begin{array}{c}
1 \\
u_{i} \\
h_{t, i}
\end{array}\right)
$$

The stator is simulated as several constant total enthalpy elements, each one connected to a volute cell and to a virtual plenum that lies between the stator and the rotor. Each stator channel generates source terms for the volute cell to which it is attached and contributes to the total flow that enters the virtual plenum. The mass flow rate $\dot{m}_{s t, i}$ for the stator channel number $i$ is:

$$
\begin{array}{r}
\left.\frac{\mathrm{d} m}{\mathrm{~d} t}\right|_{s t, i}=A_{3} \cdot C_{D_{s t}} \frac{A_{w, i}}{\sum A_{w, i}} \cdot \sin \alpha_{3} \cdot \frac{p_{2 t, i}}{\sqrt{R \cdot T_{2 t, i}}} \\
\cdot\left(\frac{p_{2 t, i}}{p_{3}}\right)^{-\frac{1}{n_{s t, i}}} \cdot \sqrt{2 \cdot \frac{\gamma}{\gamma-1} \cdot\left[1-\left(\frac{p_{2 t, i}}{p_{3}}\right)^{\frac{1-n_{s t, i}}{n_{s t, i}}}\right.}
\end{array}
$$

The stator inlet total pressure $p_{2 t, i}$ and temperature $T_{2 t, i}$ are computed in the volute cell from which the flow comes, and the stator outlet pressure $p_{3}$ is computed in the stator outlet virtual plenum. The stator outlet total surface $A_{3}$ is multiplied by the ratio between the volute cell window surface $A_{w, i}$ and the total volute window surface $\sum A_{w, i}$ and by a discharge coefficient $C_{D s t}$ to get the stator channel effective area. The polytropic coefficient $n_{s t, i}$ used during the expansion is computed using a losses model that estimates the stator total pressure loss as being proportional to the dynamic pressure at the stator inlet. This total pressure loss model is a simplified Darcy-Weisbach equation with a constant friction coefficient. Several methods to model the turbine inefficiencies can be found in [25]. The stator outlet flow angle $\alpha_{3}$ is computed using a boundary elements method (BEM). In order to compute it using BEM, the flow is supposed to be two-dimensional, homentropic and noncompressible. This way, the stator blades can be approximated as flat panels and the flow is computed using a distribution of discrete potential singularities in the panels and the origin, as schematically shown in Figure 2. The method is explained in detail in Appendix A.

The rotor is simulated as a constant rothalpy element. Its mass, momentum and total enthalpy flow is computed and used as a boundary flow for the virtual plenum and for the first cell of the turbine outlet duct. Again, the polytropic coefficient $n_{r t}$ is computed using several losses models that estimate its total pressure loss. In this case, however, the rotor relative outlet flow angle $\beta_{4}$ is imposed instead of computed. The rotor mass flow rate $\dot{m}_{r t}$ is: 


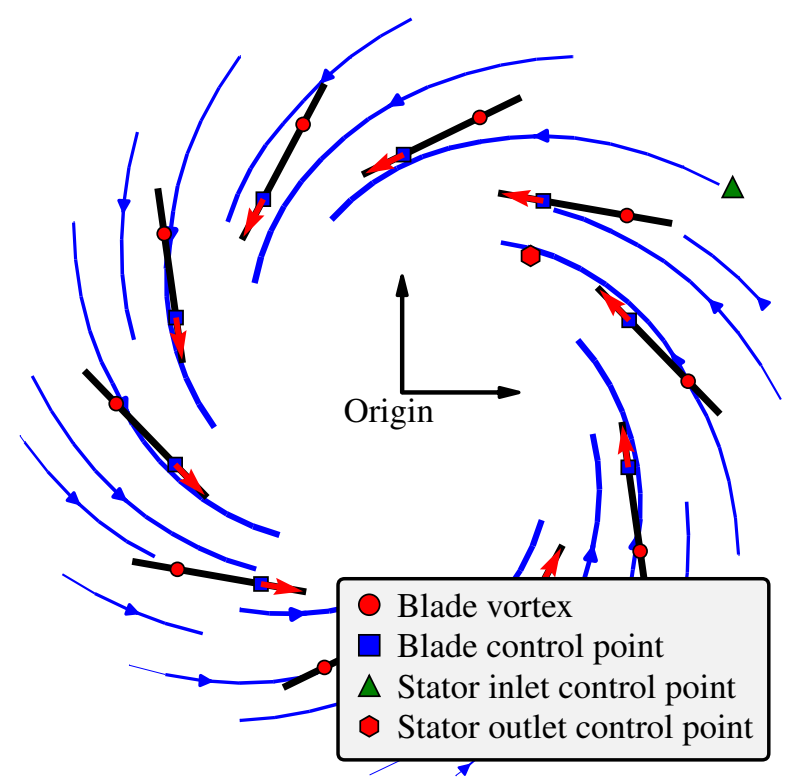

Figure 2: BEM model used to compute the stator outlet flow angle.

$$
\begin{aligned}
\left.\frac{\mathrm{d} m}{\mathrm{~d} t}\right|_{r t}= & \frac{p_{3 t, r e l}}{R \cdot T_{3 t, r e l}} \cdot\left(\frac{p_{3 t, r e l}}{p_{4}}\right)^{-\frac{1}{n_{r t}}} \cdot A_{4} \cdot \sin \beta_{4} \\
& \left\{2 \cdot \frac{\gamma}{\gamma-1} \cdot R \cdot T_{3 t, r e l} \cdot\left[1-\left(\frac{p_{3 t, r e l}}{p_{4}}\right)^{\frac{1-n_{r t}}{n_{r t}}}\right]\right. \\
& \left.-\omega^{2} \cdot\left(r_{r t, \text { in }}^{2}-\bar{r}_{r t, \text { out }}^{2}\right)\right\}^{\frac{1}{2}}
\end{aligned}
$$

The rotor inlet total relative pressure $p_{3 t, \text { rel }}$ and temperature $T_{3 t \text {,rel }}$ are computed in Equation A.25 and Equation A.24. The rotor outlet pressure $p_{4}$ is the pressure of the first computational cell of the turbine outlet duct. The rotor wheel inlet $r_{r t, i n}$ and mean outlet radius $\bar{r}_{r t \text { out }}$ and the rotor outlet section $A_{4}$ are physically measurable, while the relative outlet flow angle $\beta_{4}$ is very similar to the metal angle but has a small deflection from it.

Finally, the full model is time-integrated using a classical ordinary differential equations (ODE) solving scheme.

The model uses four adjusting parameters that can be obtained using a turbine map or CFD data: a stator passage losses coefficient $K_{s t, l o s s}$, the optimum rotor inlet flow angle $\beta_{3, \text { opt }}$, a rotor passage losses coefficient $K_{r t, l o s s, p s g}$ and the rotor outlet relative flow angle $\beta_{4}$. Other model parameters are geometric and can be obtained using CAD files or direct measurement of the turbine, if it is available.

\section{Validation and results discussion}

The simplified model has been validated against U-RANS simulations done by Galindo et al. [10]. The simulations where done using a $k-\omega$ SST model for turbulence, maintaining a $y^{+}$equal to one, which usually is the preferred model when computing turbomachinery, as seen in Galindo et al. [26]. The convective terms were computed using a second-order upwind scheme and the unsteady terms were integrated using a firstorder implicit scheme in time. $1.8^{\circ}$ of rotor turning per timestep were used, and the mesh was formed by 2 million cells. In order to take into account the rotor movement, a sliding mesh model were used. A mesh independence analysis was carried out to assess the validity of the results.

The boundary conditions consisted of an isentropic pulsating total pressure and temperature inlet and a constant static pressure outlet. The total pressure at the inlet described a pure sinusoidal evolution. The rotor speed was maintained constant. The different cases are described in Table 2.

\begin{tabular}{cccc}
\hline Case & Rotor speed & B.C. frequency & Inlet total pressure \\
\hline 1 & $90 \mathrm{krpm}$ & $50 \mathrm{~Hz}$ & $100 \mathrm{kPa}$ to $220 \mathrm{kPa}$ \\
2 & $90 \mathrm{krpm}$ & $130 \mathrm{~Hz}$ & $100 \mathrm{kPa}$ to $220 \mathrm{kPa}$ \\
3 & $180 \mathrm{krpm}$ & $50 \mathrm{~Hz}$ & $150 \mathrm{kPa}$ to $330 \mathrm{kPa}$ \\
4 & $180 \mathrm{krpm}$ & $130 \mathrm{~Hz}$ & $150 \mathrm{kPa}$ to $330 \mathrm{kPa}$ \\
\hline
\end{tabular}

Table 2: Simulated cases.

All the data has been simulated also using a totally unidimensional equivalent volute, while keeping the stator and rotor models. As there is no information about the stator inlet angle using this approach, the stator outlet angle has been set to the mean value obtained from the $3 \mathrm{D}$ simulations.

Figure 3 shows the turbine inlet corrected mass flow rate $\dot{m}_{1}^{*}$ versus the turbine total to static expansion ratio, $p_{1 t} / p_{5}$. The turbine inlet corrected mass flow rate is described as:

$$
\dot{m}_{1}^{*}=\dot{m}_{1} \cdot \sqrt{\frac{T_{1 t}}{T_{\text {ref }}}} \cdot \frac{p_{r e f}}{p_{1 t}}
$$

where the reference temperature is $T_{\text {ref }}=288.15 \mathrm{~K}$ and the reference pressure $p_{\text {ref }}=101325 \mathrm{~Pa}$. The figure shows good agreement between the CFD computation and the simplified model results. At the highest frequency, the amplitude of the oscillation is slightly overestimated using the old volute model, while the quasi-bidimiensional approximation shows better behaviour.

The corrected mass flow rate for the stator $\dot{m}_{s t}^{*}$ and the rotor $\dot{m}_{r t}^{*}$ are shown in Figure 4 and Figure 5. Their mass flow rates are corrected using the stator inlet total pressure and temperature and the rotor inlet total pressure and temperature, respectively. Again, the results are satisfactory in both cases. The rotor shows its biggest discrepancies at high speeds and low expansion ratios: this can be explained by the constant rotor outlet relative flow angle approach, and should be corrected in future works. In these cases, the amplitude of the mass flow rate oscillation is higher and better reproduced using the quasibidimensional volute.

Figure 6 shows the results for the stator outlet flow angle. The simplified model is not able to reproduce the biggest oscillations. However, this does not suppose big problems in the turbine power output nor its mass flow rate. The potential stator hypothesis can't stand against the fact that, when the biggest discrepancies appear, the expansion ratio and, thus, the flow 
speed is very low, easing the appearance of non-isentropic behaviour such as boundary layer and wake growth and flow detachment, a can be seen in Figure 7. In this figure, streamlines are plotted at two different times for case 2. At the lowest expansion ratio, the flow is almost tangential to the rotor and flow detachments appear. This kind of flow behaviour is not taken into account using potential flow theory and, thus, can not be computed properly without further refinements of the model. Flow detachment appear at stator expansion ratios less than 1.15 and turbine expansion ratios around 1.5 in the turbine that the authors studied, but further studies are needed to give a general rule for different turbines.

Figure 8 shows the differences between the CFD and the simple model stator polytropic coefficient. The mean value and some of the variations are correctly taken into account, but the model underestimates the amplitude of the oscillation. The cases at $90 \mathrm{krpm}$ where simulated with a very broad range of expansion ratios, even generating negative power output. At very low expansion ratios, the polytropic coefficient experiences large variations, presumably due to flow detachment. The differences in the streamlines are clearly visible in Figure 7, where the same case is plotted for a high expansion ratio and a low expansion ratio. At high expansion ratios, the flow is perfectly attached to the stator blade, while recirculation bubbles and full detachments appear in the very low expansion ratio case. While the stator head loss is approximately proportional to the dynamic pressure at its inlet in quasi-stationary or low frequency boundary conditions with attached flow, it begins to differ as accumulation effects and flow detachments rise.

Figure 9 shows the differences between the CFD and the simple model rotor polytropic coefficient. Again, large variations appear at very low expansion ratios. Albeit not perfectly, the general shape of the polytropic coefficient excursion is reproduced and, thus, the power output is satisfactorily computed: as can be seen in Table 3 and in Figure 10, the error committed while computing the power output is small. As in the stator case, the flow recirculates at very low expansion ratios, difficulting the polytropic coefficient estimation. A possible improvement in the accuracy could be achieved by means of two-zone modelling during recirculation events, using different models for attached and detached flow.

Figure 10 shows the turbine power output plotted against the turbine expansion ratio. The biggest errors appear at the highest expansion ratios, where the polytropic coefficient is underestimated, and at the lower expansion ratios, where it is overestimated. Further refinements of the losses modelling should correct this discrepancies.

Figure 11 shows the volute outlet velocity distribution at four different times for the case at $181 \mathrm{krpm}$ and $130 \mathrm{~Hz}$. The volute outlet speed is plotted against an angular coordinate: this angular coordinate begins at the volute tongue, with positive angles measured in the normal flow direction. The model has been computed using an unusually large number of cells for the volute, 90. The stator screws generate some blockage effect, so the volute outlet surface has been reduced in the presence of these fixing screws. The simple model is able to reproduce the dynamic behaviour across the volute, what it is expected to give it better high frequency prediction capabilities than more simple models, like using an straight duct for computing the volute. Figure 12 shows the volute total temperature at different angular positions. Again, the model is able to estimate this temperature distribution across the volute thanks to the quasi-bidimensional approach for volute modelling, giving results that can not be accomplished with a more simple equivalent one-dimensional duct.

\begin{tabular}{cccc}
\hline Case & CFD & Simplified model & Error \\
\hline 1 & $2867.1 \mathrm{~W}$ & $2800.0 \mathrm{~W}$ & $2.3 \%$ \\
2 & $2841.7 \mathrm{~W}$ & $2794.2 \mathrm{~W}$ & $1.7 \%$ \\
3 & $9160.3 \mathrm{~W}$ & $8978.5 \mathrm{~W}$ & $2.0 \%$ \\
4 & $9113.7 \mathrm{~W}$ & $8943.7 \mathrm{~W}$ & $1.9 \%$ \\
\hline
\end{tabular}

Table 3: Turbine power output $\dot{W}$ error.

It has been shown that, while the overall turbine power output error is small, there are some problems at high expansion ratios. This is expected to happen due to two different limitations of the current model: the rotor outlet flow angle is fixed for all operating conditions and the losses models underestimate the polytropic coefficient at high expansion ratios. As losses coefficients are adjusted for a fixed flow angle while in the CFD simulation vary, their values are not optimally selected. A more realistic rotor outlet flow angle model should enhance the model results. Also, at very low expansion ratios flow detachment and even inverse rotor and stator flow may appear, while the current model can not compute properly these situations. These effects limit the extrapolation capabilities of the presented model and will be taken into account in future works. 

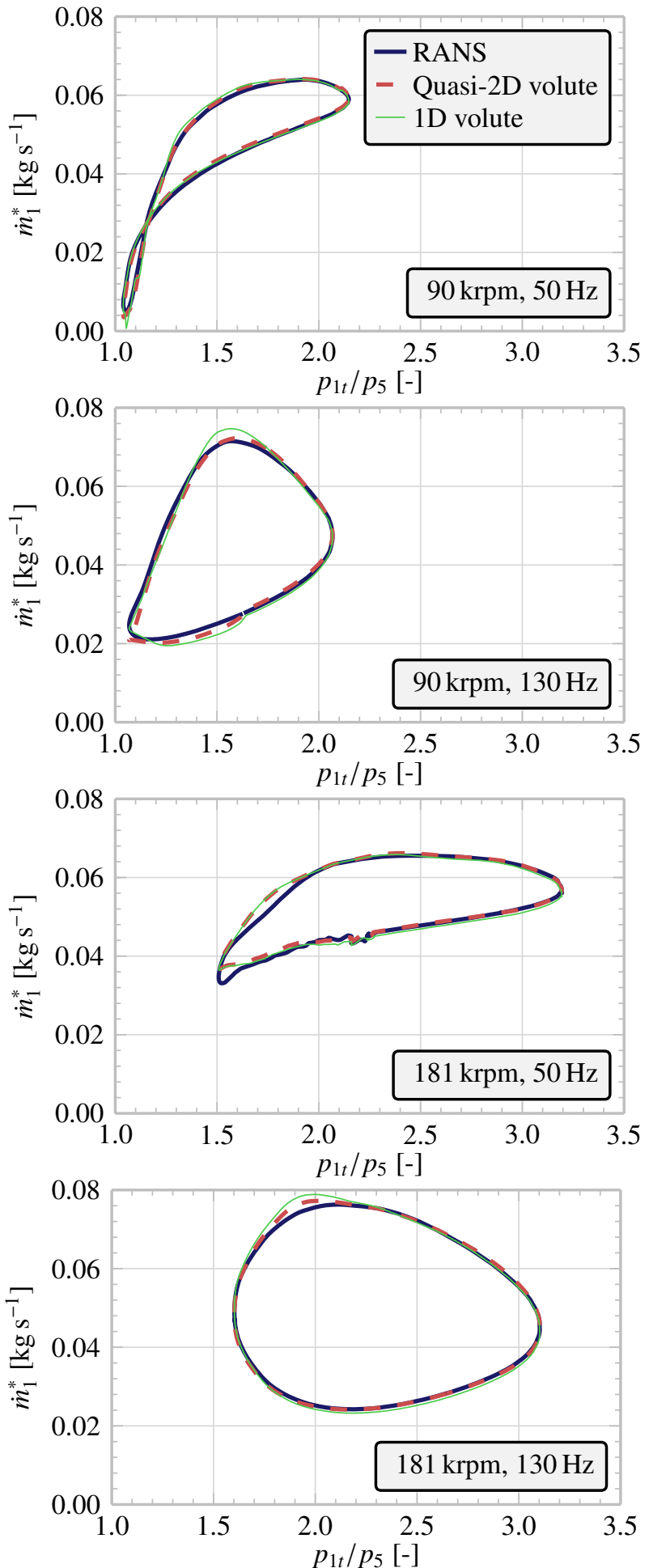

Figure 3: Turbine inlet corrected mass flow rate $\dot{m}_{1}^{*}$ vs. the turbine total to static expansion ratio $p_{1 t} / p_{5}$.
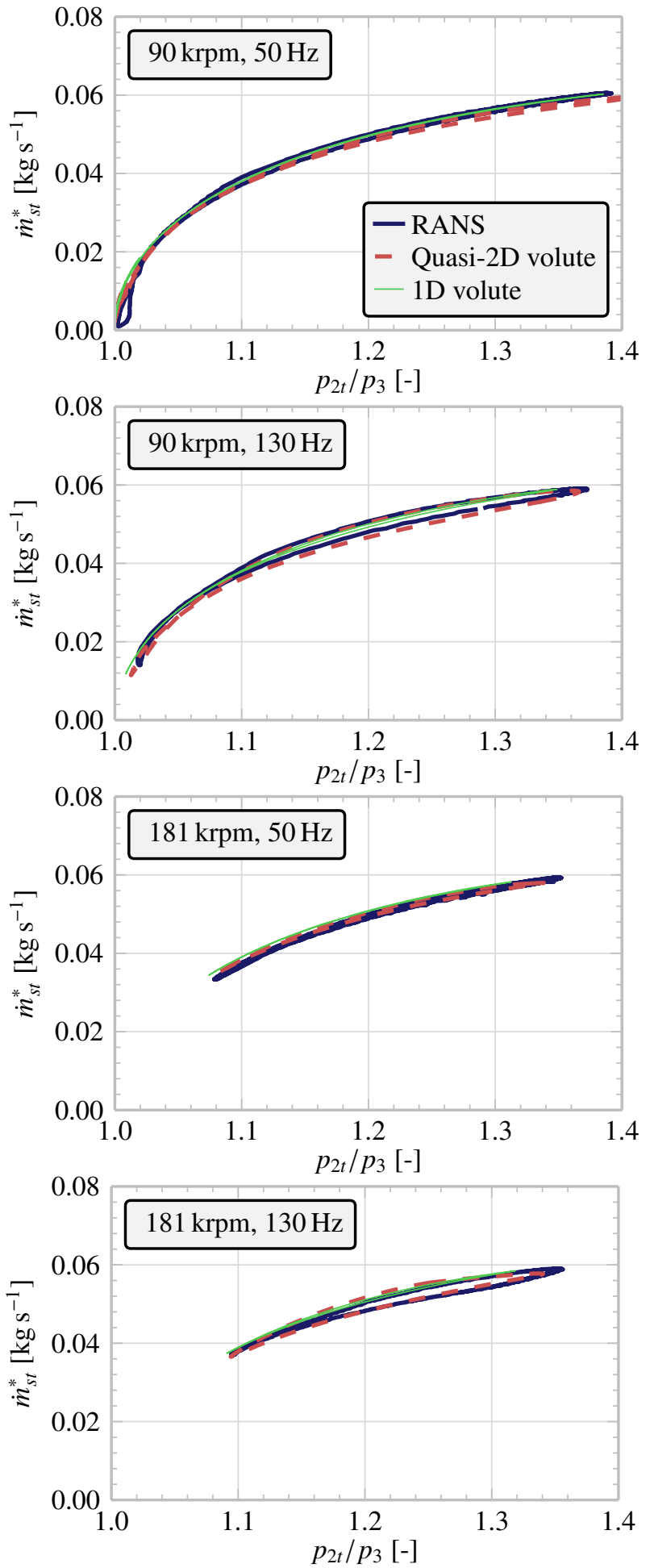

Figure 4: Stator corrected mass flow rate $\dot{m}_{s t}^{*}$ vs. the stator total to static expansion ratio $p_{2 t} / p_{3}$. 

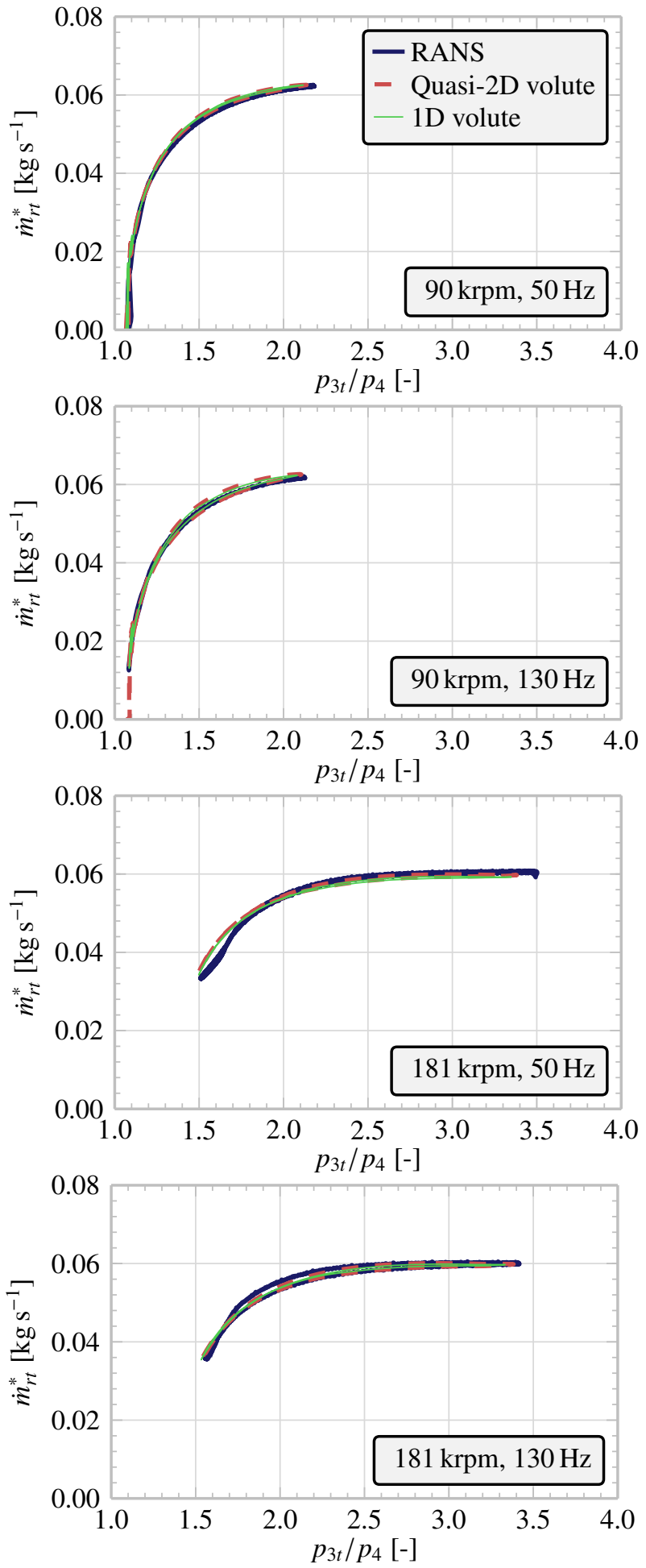

Figure 5: Rotor corrected mass flow rate $\dot{m}_{r t}^{*}$ vs. the rotor total to static expansion ratio $p_{3 t} / p_{4}$.
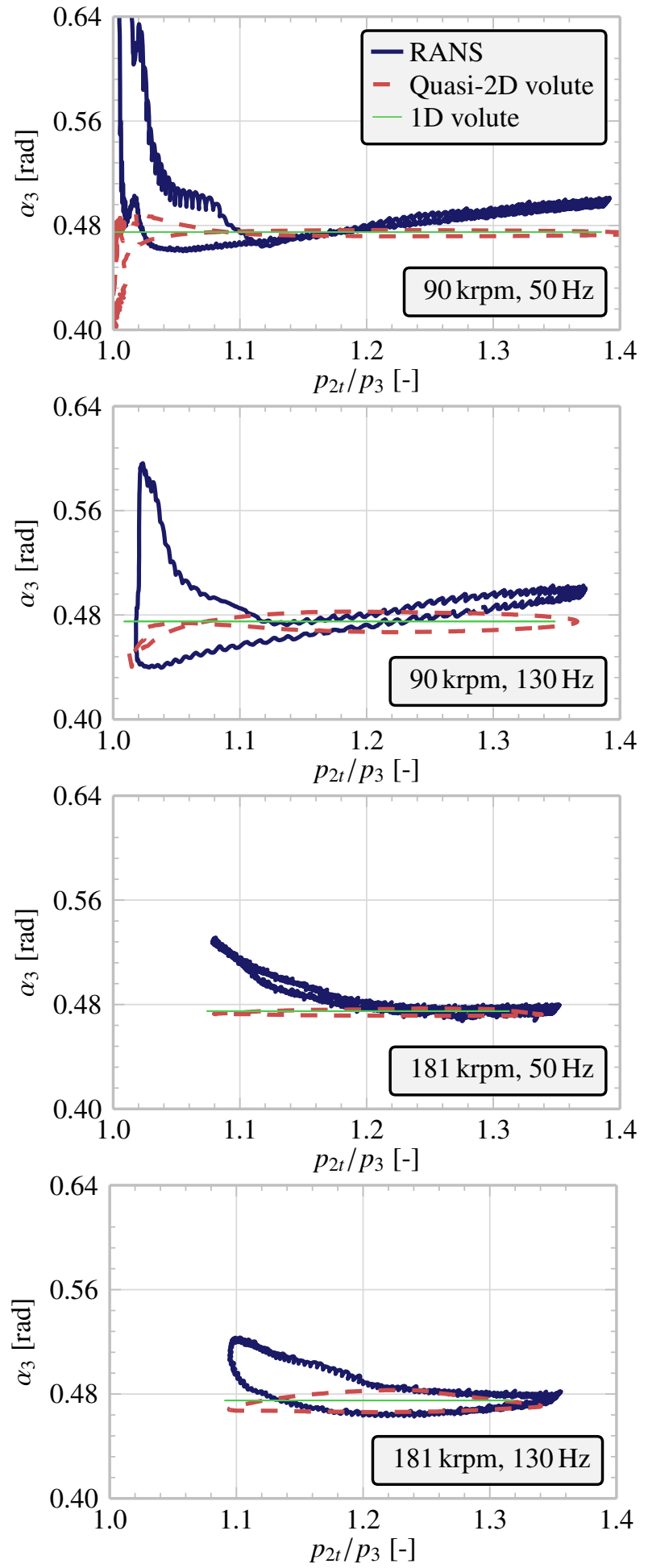

Figure 6: Stator outlet flow angle $\alpha_{3}$ vs. the stator total to static expansion ratio $p_{2 t} / p_{3}$. 
$90 \mathrm{krpm}, 130 \mathrm{~Hz}$, very high expansion ratio

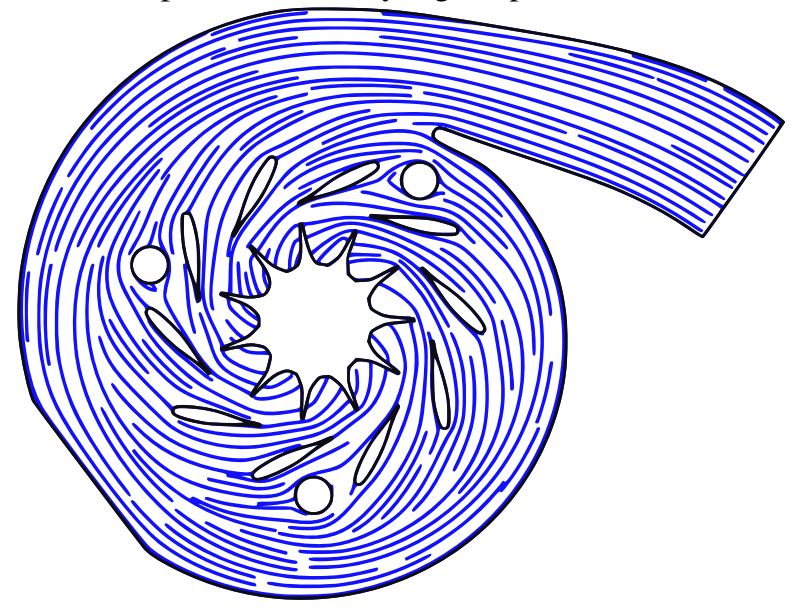

$90 \mathrm{krpm}, 130 \mathrm{~Hz}$, very low expansion ratio

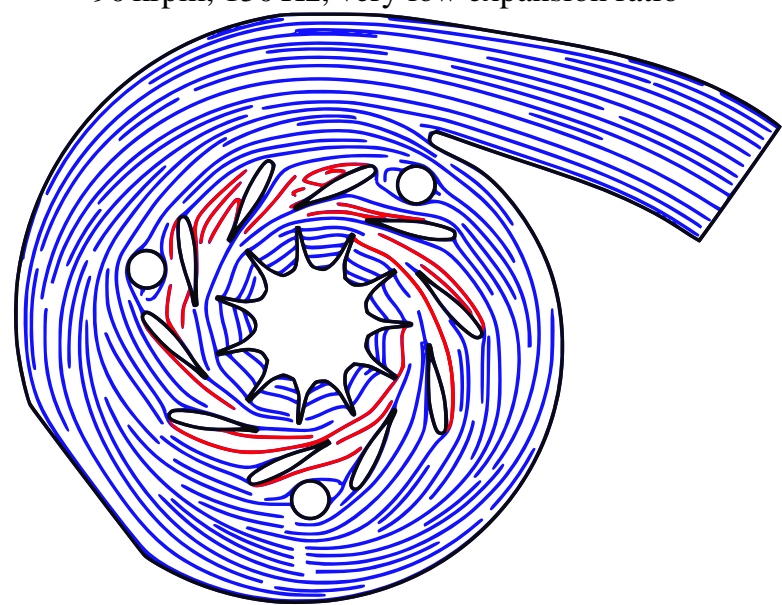

Figure 7: Stream lines at two different expansion ratios.
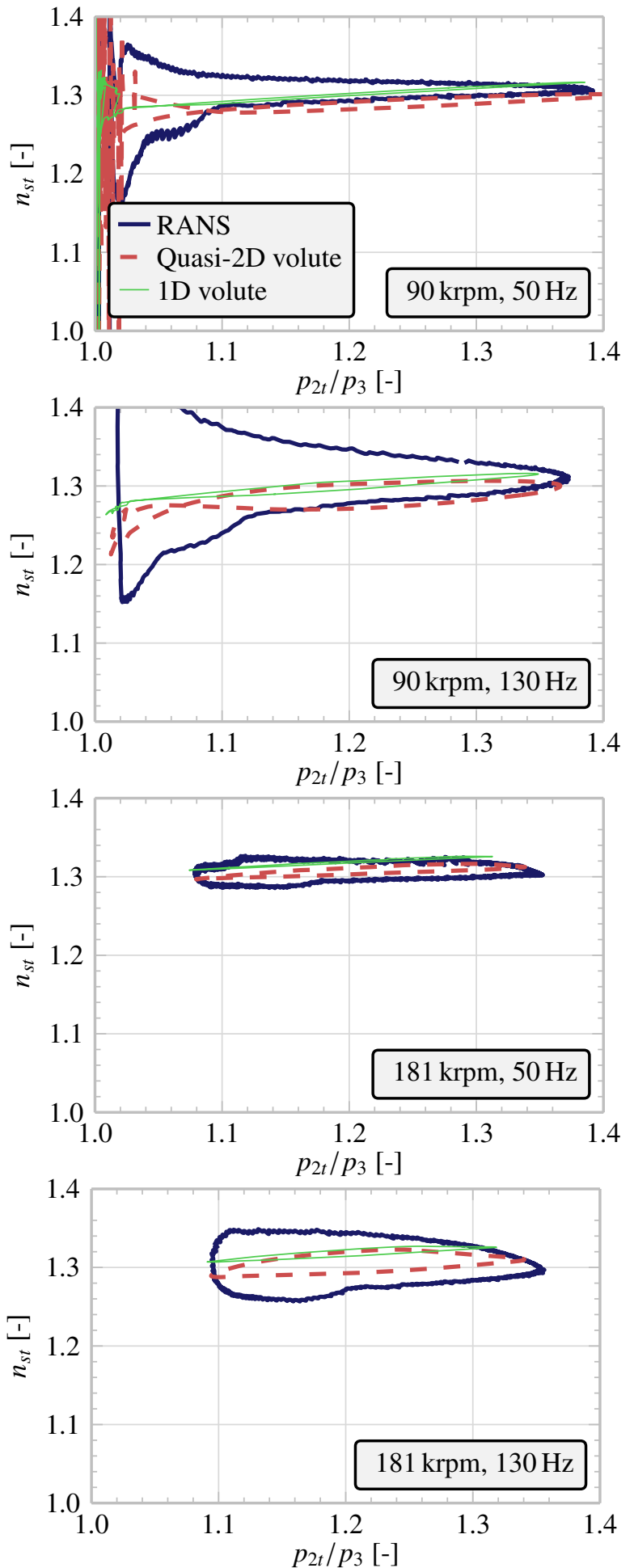

Figure 8: Stator polytropic coefficient $n_{s t}$ vs. the stator total to static expansion ratio $p_{2 t} / p_{3}$. 

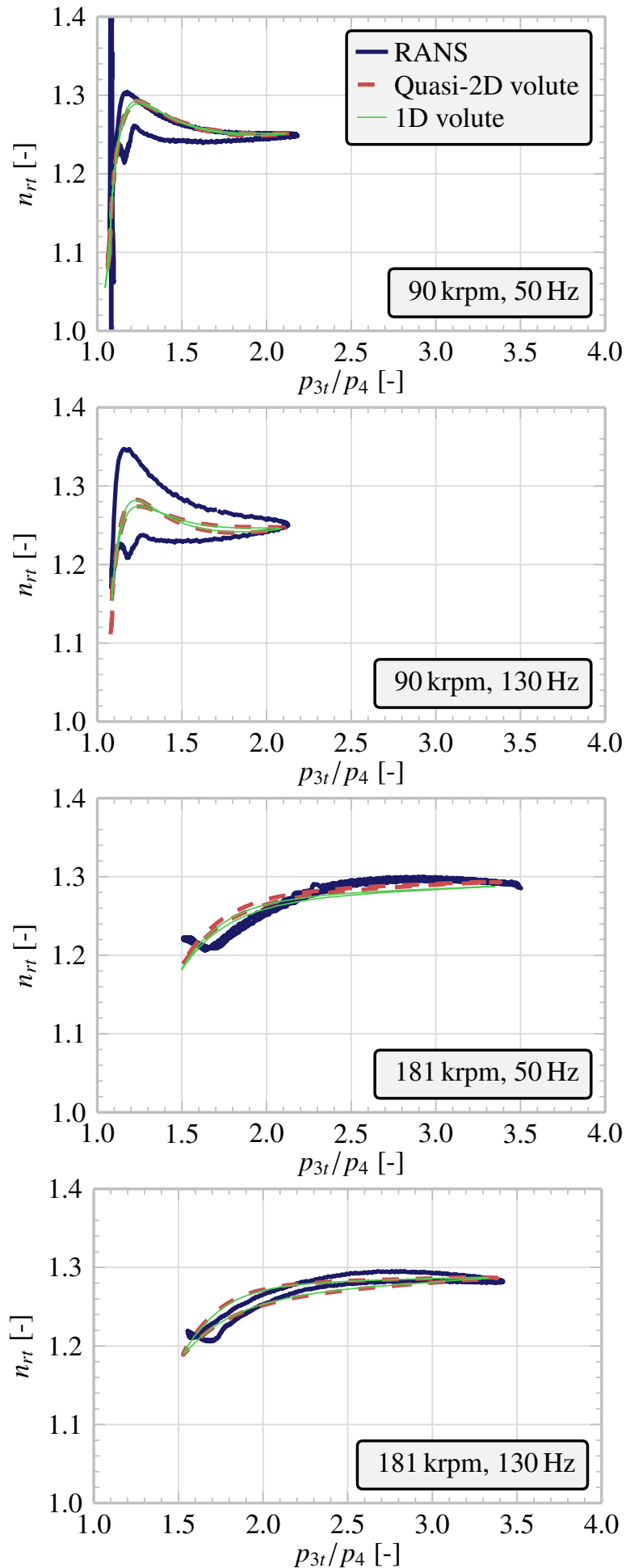

Figure 9: Rotor polytropic coefficient $n_{r t}$ vs. the rotor total to static expansion ratio $p_{3 t} / p_{4}$.
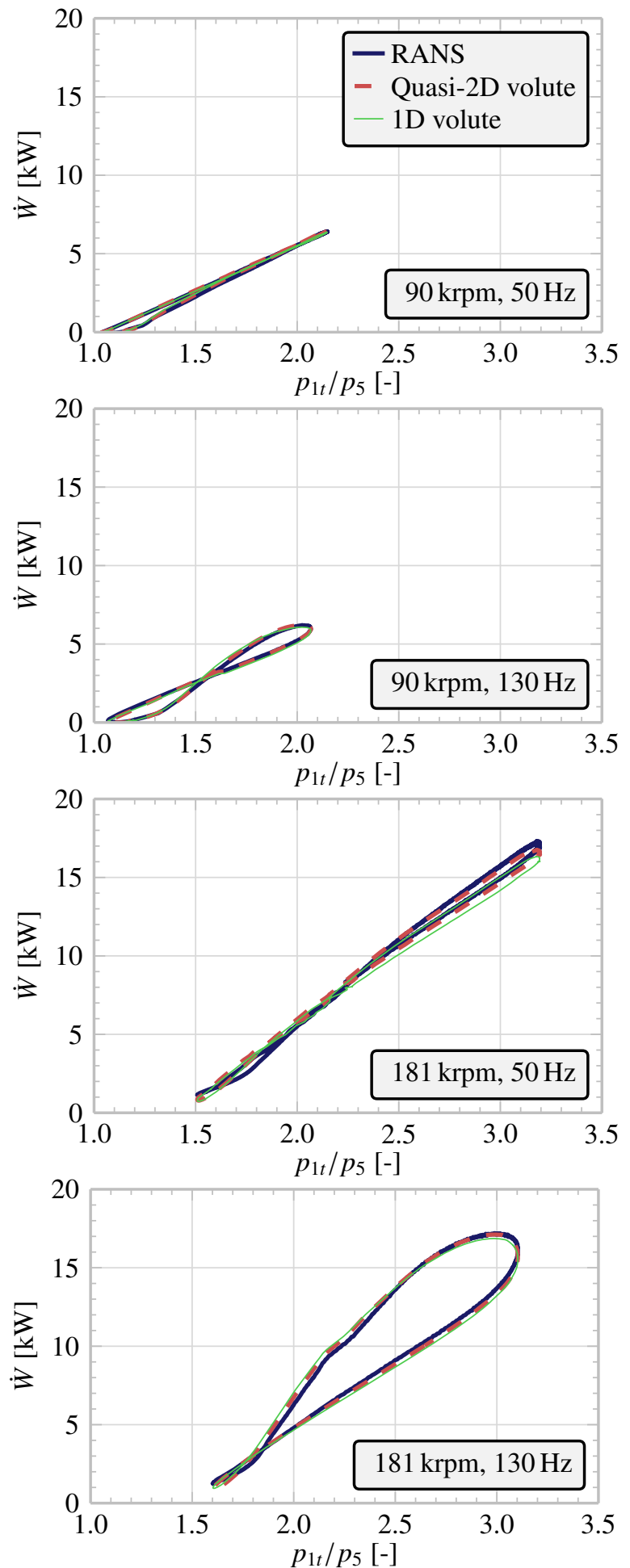

Figure 10: Turbine power output $\dot{W}$ vs. the turbine total to static expansion ratio $p_{1 t} / p_{5}$. 

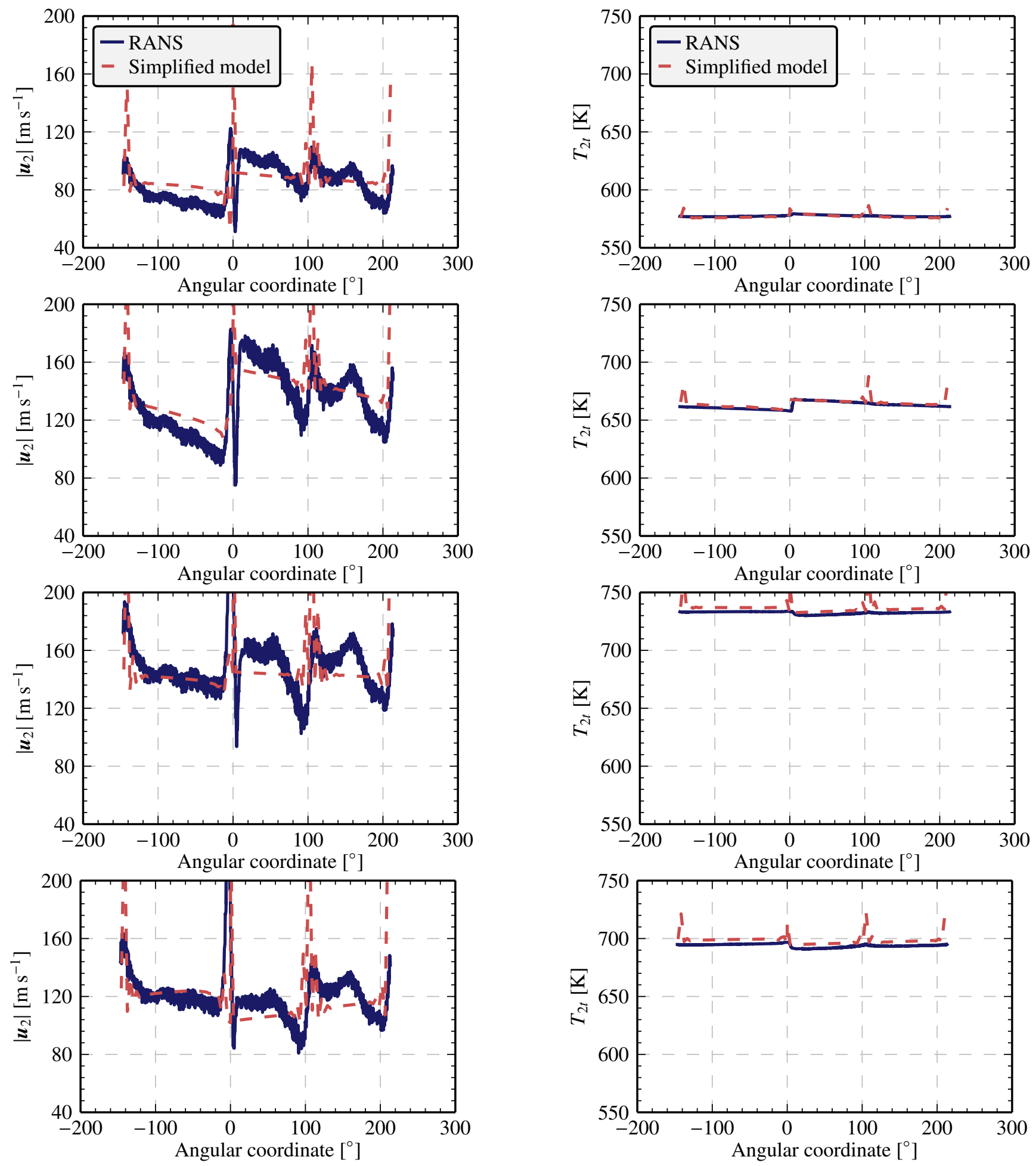

Figure 11: Volute outlet speed $\boldsymbol{u}_{2}$ for $181 \mathrm{krpm}$ and $130 \mathrm{~Hz}$.

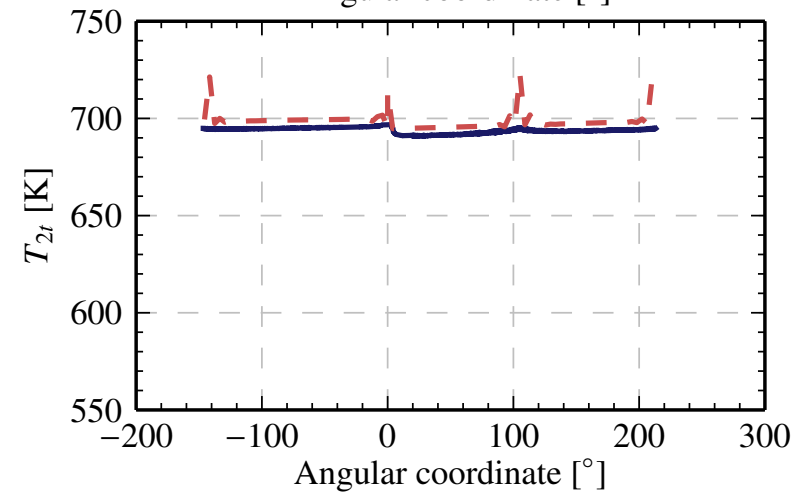

Figure 12: Volute total temperature $T_{2 t}$ for $181 \mathrm{krpm}$ and $130 \mathrm{~Hz}$. 


\section{Conclusions}

This paper describes a simple turbine model aimed to be used for transient pulsating flow applications typical of engine development. The model has proved to successfully reproduce the behaviour obtained by U-RANS simulations of an automotive radial turbine at different operating speeds and pressure oscillation frequencies.

As the main accumulation and wave effects occur in the volute, an upgrade from the classic equivalent straight one-dimensional duct is needed to better compute the turbine response at very high frequencies. The turbine model presented here has not been tested with high frequency boundary conditions, but it shows promising results while computing the characteristics of the flow across the volute. At $130 \mathrm{~Hz}$, the wave length is about $3.8 \mathrm{~m}$ for the tested cases, while the volute length is about $0.25 \mathrm{~m}$, only an order of magnitude smaller: the wave effects are important enough to be seen in Figure 11 and Figure 12, and the model is able to capture them. Also, both the mass flow rate and the turbine power output is better reproduced using the quasi-bidimensional turbine than with a classical onedimensional model of the volute. With classical equivalent onedimensional volute models some of the accumulation and wave effects are captured, but their results are inherently less capable of capturing high frequency effects: at any given time, there could be important differences in the flow characteristics at different positions inside the volute that can not be computed. With the quasi-bidimensional volute, different stator channels may be subjected to different inlet conditions, while with the fully one-dimensional volute there is only one equivalent stator channel exposed to the duct outlet conditions. It is even possible to use different volute window areas for each cell in case that in the real turbine some channel blockage is expected due to mounting screws. The quasi-bidimensional model is also trivially adapted to twin-entry and waste-gate turbines.

Also, it has been demonstrated that a BEM model is able to compute the stator outlet flow angle with good precision even for transient pulsating flow applications only by imposing basic geometric information. This is specially important in order to compute the turbine behaviour at stator angles not represented in the turbine map: the angle does not need to be interpolated but can be directly computed. With more complex vane geometries it should be possible to get good results by rising the number of panels used to approximate the blades. The BEM model starts to fail with low expansion ratios due to the flow being too distant from homentropic conditions but behaves well at high Mach number. In order to improve the predictions with wide wakes and flow detachments while maintaining low computational costs, general correlations coupled with the current model should be developed.

The small hysteretic behaviour of the stator and the rotor is also approximated, although it has low influence in the global behaviour of the turbine at low and medium frequencies. At very high frequencies, however, it is expected that this hysteretic effects will grow.

In order to improve and test the presented model, the following works will be made:
- Test the model at high frequencies $(1000 \mathrm{~Hz}$ and higher).

- Test the model with more complex stator geometries.

- Improve rotor modelling by computing its outlet relative flow angle.

- Improve stator and rotor losses modelling.

- Test whether general correlations for stator outlet flow angle and polytropic coefficients at very low expansion ratios and, thus, partially detached flow are feasible.

\section{Appendix A. Detailed model description}

In this section, the model will be described in detail. First, the method used to compute one-dimensional models will be described, including the special case of the volute. Then, the stator model will be presented. Last, the rotor model will be shown.

\section{Appendix A.1. One-dimensional elements}

One-dimensional elements such as the inlet and outlet are discretised using a finite-volume approach, dividing each one in computational cells that are described by their state vector:

$$
\boldsymbol{w}=\left(\begin{array}{c}
\rho \\
\rho \cdot u \\
\rho \cdot e_{t}
\end{array}\right)=\left(\begin{array}{c}
\rho \\
\rho \cdot u \\
\rho \cdot c_{v} \cdot T+\rho \cdot u^{2} / 2
\end{array}\right)
$$

where $\rho$ is the density, $u$ is the fluid speed, $c_{v}$ is the specific heat capacity at constant volume, $T$ is the fluid temperature and $p$ is the fluid pressure. Also, an ideal gas law is used

The finite-volume problem is computed using a Godunov's scheme, as first described in the work by the mentioned author [27]:

$$
\frac{\mathrm{d} \overline{\boldsymbol{w}}_{\boldsymbol{i}}}{\mathrm{d} t}=\frac{\left(A_{i-1, i} \cdot \boldsymbol{F}_{i-1, i}-A_{i, i+1} \cdot \boldsymbol{F}_{i, i+1}+\boldsymbol{C}_{i}\right)}{V_{i}}
$$

where $t$ is the time, $\overline{\boldsymbol{w}}_{i}$ represents the mean value of the state vector in the cell $i, A_{i-1, i}$ is the boundary surface between cell $i-1$ and cell $i, \boldsymbol{F}_{i-1, i}$ is the flow vector between cells $i-1$ and $i$, $C_{i}$ is the source terms vector affecting cell $i$ and $V_{i}$ is the volume of the cell.

The source term is computed as:

$$
\boldsymbol{C}_{i}=\left[\begin{array}{c}
0 \\
p_{i} \cdot\left(A_{i-1, i}-A_{i, i+1}\right) \\
0
\end{array}\right]
$$

The flow vector is obtained by using an approximate Riemann solver: several methods has been implemented to asses their validity for this particular problem. Equation A.2 is solved iteratively using a classical ODE solver: again, several solvers has been implemented and tested. The time-step $\Delta t$ is chosen at each integration step in order to obey the Courant-FriedrichsLewy (CFL) condition [28]. 
In order to improve the spatial accuracy of the integration, a second order Monotone Upstream-centered Schemes for Conservation Laws (MUSCL) scheme has been implemented. In a MUSCL scheme, as described by van Leer in [21], the state vector is reconstructed at each side of the boundary between two cells at the beginning of each time-step using a linear or higher order extrapolation, limiting this extrapolation so the scheme obtains total variation diminishing (TVD) properties. A linear extrapolation has been chosen, so second order accuracy is obtained where the state vector is smooth enough, degrading the solution to first order where sharp discontinuities are present. Several limiter functions have been implemented and tested, finding only small differences between them.

The connection between one-dimensional elements is computed using a virtual duct consisting of four cells: two for the ending of the first element and other two for the start of the other element. This way, the flow vector between the second and the third virtual cells is the flow that leaves the last cell of the first element and the one that enters the first cell of the second element, maintaining second order TVD properties in the boundary condition.

In the particular case of the volute, the flow is supposed to be fundamentally one-dimensional except for the small lateral window that connects it with the stator: at each time-step the stator is solved as a boundary condition that generates additional source terms in the volute. Each volute cell is connected to a stator channel:

$$
C_{i}=\left(\begin{array}{r}
\left.\frac{\mathrm{d} m}{\mathrm{~d} t}\right|_{s t} \\
\left.\frac{\mathrm{d} m}{\mathrm{~d} t}\right|_{s t} \cdot u \\
\left.\frac{\mathrm{d} m}{\mathrm{~d} t}\right|_{s t} \cdot c_{p} \cdot T_{t}
\end{array}\right)_{i}
$$

where $\left.\frac{\mathrm{d} m}{\mathrm{~d} t}\right|_{s t i}$ is the mass flow rate that goes through the volute window at cell $i$ to the stator. This source terms vector is summed with the normal source terms vector. The volute has other particularity: its end is connected to its inlet, so some recirculation is possible. The volute inlet is, thus, connected to the volute outlet and to the turbine inlet duct outlet.

The stator model also maintains some accumulation effects and it is partly simulated as an equivalent cell with a volume equal to the actual volume occupied by the real stator. The flow vector that enters the stator is computed as:

$$
\boldsymbol{F}=\left[\begin{array}{c}
\left.\sum \frac{\mathrm{d} m}{\mathrm{~d} t}\right|_{s t, i} \\
0 \\
\sum\left(\left.\frac{\mathrm{d} m}{\mathrm{~d} t}\right|_{s t} \cdot c_{p} \cdot T_{t}\right)_{i}
\end{array}\right]^{2}
$$

and the flow vector that leaves the stator and enters the rotor is:

$$
\boldsymbol{F}=\left(\begin{array}{c}
\left.\frac{\mathrm{d} m}{\mathrm{~d} t}\right|_{r t} \\
0 \\
\left.\frac{\mathrm{d} m}{\mathrm{~d} t}\right|_{r t} \cdot c_{p} \cdot T_{3 t}
\end{array}\right)
$$

where $\left.\frac{\mathrm{d} m}{\mathrm{~d} t}\right|_{r t}$ is the mas flow rate that goes through the rotor and $T_{3 t}$ is the total temperature at the stator finite-volume cell. The presence of this stator cell not only provides accumulation effects for the stator, but also uncouples the rotor from the stator flow: as this is known at the stator cell at the beginning of each time-step, it can be used as an input for the rotor flow simulation instead of solving the coupled stator-rotor system.

Finally, the flow that enters the boundary between the rotor and the turbine outlet is:

$$
\boldsymbol{F}=\left(\begin{array}{c}
\left.\frac{\mathrm{d} m}{\mathrm{~d} t}\right|_{r t} \\
\left.\frac{\mathrm{d} m \mid}{\mathrm{d} t}\right|_{r t} w_{4} \cdot \sin \beta_{4}+p_{4} \\
\left.\frac{\mathrm{d} m}{\mathrm{~d} t}\right|_{r t} \cdot c_{p} \cdot T_{4 t}
\end{array}\right)
$$

where $w_{4}$ is the rotor outlet relative speed, $\beta_{4}$ is the rotor outlet relative flow angle and $T_{4 t}$ is the total temperature at the rotor outlet.

\section{Appendix A.2. Stator flow}

Each stator channel outlet speed is computed assuming a constant total enthalpy evolution:

$$
\begin{aligned}
T_{2 t i} & =T_{3 t i} \Rightarrow u_{s t, i}=\left.\sqrt{2 \cdot c_{p} \cdot\left(T_{2 t}-T_{3}\right)}\right|_{i} \\
& =\left.\sqrt{2 \cdot R \cdot \frac{\gamma}{\gamma-1} \cdot T_{2 t} \cdot\left[1-\left(\frac{p_{2 t}}{p_{3}}\right)^{\frac{1-n_{s t}}{n_{s t}}}\right]}\right|_{i}
\end{aligned}
$$

where $u_{s t i}$ is the stator outlet speed for the stator channel connected to the volute cell $i, n_{s t}$ is the polytropic coefficient of the evolution, the conditions at the stator inlet $T_{2 t i}$ and $p_{2 t i}$ are computed in the cell $i$ at the volute and the pressure $p_{3}$ is the pressure computed at the cell that represents the accumulation effects of the stator.

To compute the mass flow rate, the stator outlet density is needed:

$$
\begin{aligned}
\rho_{3} & =\frac{p_{3}}{R \cdot T_{3}}=\frac{p_{3}}{p_{2 t, i}} \cdot \frac{T_{2 t, i}}{T_{3}} \cdot \frac{p_{2 t, i}}{R \cdot T_{2 t, i}} \\
& =\frac{p_{2 t, i}}{R \cdot T_{2 t, i}} \cdot\left(\frac{p_{2 t, i}}{p_{3}}\right)^{-\frac{1}{n_{s t}}}
\end{aligned}
$$


The mass flow rate that flows outside the volute cell $i$ is:

$$
\begin{aligned}
\left.\frac{\mathrm{d} m}{\mathrm{~d} t}\right|_{s t, i}= & A_{3} \cdot C_{D s t} \frac{A_{w, i}}{\sum A_{w, i}} \cdot \sin \alpha_{3} \\
& \cdot\left[\frac{p_{2 t}}{R \cdot T_{2 t}} \cdot\left(\frac{p_{2 t}}{p_{3}}\right)^{-\frac{1}{n_{s t}}} \cdot u_{s t}\right]_{i}
\end{aligned}
$$

where $C_{D s t}$ represents a discharge coefficient that reflects that the area at the compressor outlet is partially blocked by the rotor blades, $A_{w i}$ is the volute window surface at cell $i$ and $\alpha_{3}$ is the absolute stator outlet angle, i.e., the flow angle measured in an inertial reference frame fixed in the turbine body. $\alpha_{3}$ is equal to 0 when the flow is fully tangential and travels in the same direction than the rotor blades, and is equal to $\pi / 2$ when the flow is fully radial. The stator outlet mean speed $u_{s t}$ can be computed using this mass flow rate:

$$
u_{s t}=\frac{\left.\sum u_{s t, i} \cdot \frac{\mathrm{d} m}{\mathrm{~d} t}\right|_{i}}{\left.\sum \frac{\mathrm{d} m}{\mathrm{~d} t}\right|_{i}}
$$

$C_{D s t}$ is computed as follows:

$$
C_{D s t}=\frac{A_{3}-A_{r t, i n, b l}}{A_{3}}=\frac{2 \cdot \pi \cdot r_{r t, i n} \cdot y_{s t}-A_{r t, b l}}{2 \cdot \pi \cdot r_{r t, i n} \cdot y_{s t}}
$$

where $A_{3}$ is the stator outlet surface, $A_{r t, i n, b l}$ is the surface blocked by the rotor blades at its inlet, $r_{r t, i n}$ is the rotor inlet radius and $y_{s t}$ is the stator height.

In the case that very large expansion ratio occurs in the stator, the flow will become choked: to compute this situation, the following procedure is used:

- The stator outlet pressure that generates choked flow is computed, see Equation A.13.

- The evolution is calculated between the stator total inlet pressure and the stator outlet pressure that generates choke.

- The stator outlet speed is computed iteratively in order to comply with the following:

- The mass flow rate should be that of sonic blockage.

- The total temperature is conserved.

- The ideal gas law is obeyed.

In choke conditions, the stator outlet speed is equal to the speed of sound. This gives the following equation:

$$
p_{3, c h, i}=p_{2 t, i} \cdot\left(\frac{\gamma+1}{2}\right)^{\frac{n_{s t, i}}{1-n_{s t, i}}}
$$

To compute the polytropic coefficient found in Equation A.10, the real evolution is divided in two effective simple ideal processes, which are shown schematically in Figure A.13:
- An evolution from $p_{2 t}$ to $p_{2 t}-\Delta p_{s t, l o s s}$, where some total pressure is dissipated increasing the specific entropy.

- An isentropic evolution from $p_{2 t}-\Delta p_{s t, l o s s}$ to $p_{3}$.

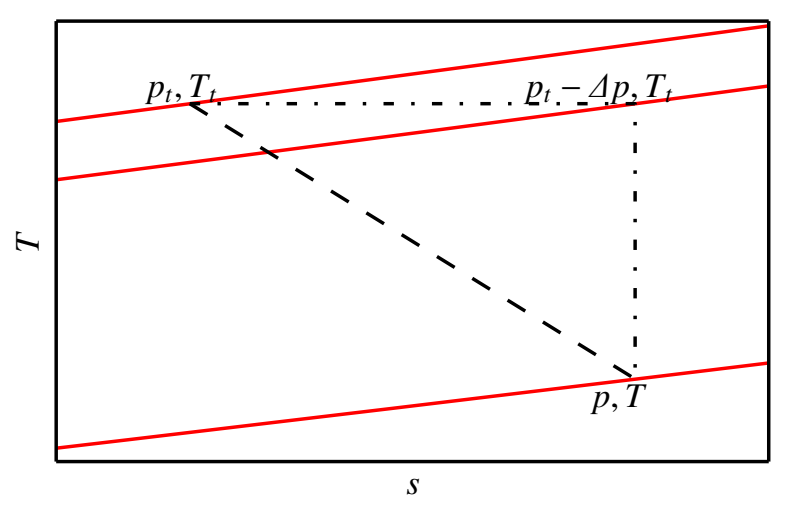

Figure A.13: Schematic evolution for modelling losses.

This evolution is equivalent to the direct one with a polytropic coefficient:

$$
\left(\frac{p_{2 t}}{p_{3}}\right)^{\frac{n_{s t}-1}{n_{s t}}}=\left(\frac{p_{2 t}-\Delta p_{s t, l o s s}}{p_{3}}\right)^{\frac{\gamma-1}{\gamma}}
$$

The dissipated stagnation pressure due to losses in the stator is assimilated to the losses in a passage due to turbulence, which are proportional to the dynamic pressure:

$$
\Delta p_{s t, l o s s}=K_{s t, l o s s} \cdot \frac{\rho_{2} \cdot\left|\boldsymbol{u}_{i}\right|^{2}}{2}
$$

where the dynamic pressure is that of the stator inlet, taking into account both components of the speed (tangential and radial):

$$
\rho_{2} \cdot\left|\boldsymbol{u}_{i}\right|^{2}=\rho_{2} \cdot u_{i}^{2}+\left.\frac{\mathrm{d} m}{\mathrm{~d} t}\right|_{s t, i} \cdot \frac{1}{A_{w, i}}
$$

where the tangential speed has been approximated by the mean tangential speed in the volute cell and the radial speed is computed using the mass flow rate that leaves the volute cell by its window. In order to accelerate the computation, the mass flow rate used to compute the losses can be the one from the last time-step.

Finally, the stator flow angle is approximated assuming bidimensional, inviscid, uncompressible and homentropic conditions. It is important to note that these assumptions are only used to compute the stator outlet flow angle. This way, there is potential flow in the stator and the speed can be computed solving Laplace's equation.

Laplace's equation can be solved using a boundary elements method (BEM), as can be seen in the work from Katz and Plotkin [29]:

- Each stator blade is discretised as a single panel.

- A point vortex singularity is placed in the quarterchord point. 
- The flow is forced to be tangential to the three-quarterchord point.

- The flow has polar periodicity.

- A point vortex singularity is placed in the centre of the stator plane.

- An unitary point sink singularity is placed in the centre of the stator plane.

- The speed is forced to have the same mean angle at the stator inlet as it has at the volute outlet in the last integration step.

- After solving the BEM problem, the speed angle is obtained at the stator outlet control point.

This simplified model can be seen in Figure 2. In this figure, the stator blades are descretised as single flat panels and the flow is forced to be tangential to the three-quarter-chord points and to the known stator inlet flow from the last time-step. The blades may be discretised with more panels if a lack of accuracy is observed with only one element per blade.

The induced speed at point $\boldsymbol{p}$ due to an unitary sink singularity at point $s$ is:

$$
\boldsymbol{u}_{\operatorname{sink}}(\boldsymbol{p}, \boldsymbol{s})=-\left(\begin{array}{c}
\frac{\cos \theta}{2 \cdot \pi \cdot|\boldsymbol{p}-\boldsymbol{s}|} \\
\frac{\sin \theta}{2 \cdot \pi \cdot|\boldsymbol{p}-\boldsymbol{s}|}
\end{array}\right)
$$

where $\theta$ is the angle formed between the radius vector $\boldsymbol{p}$ and the radius vector $s$. The induced speed at point $\boldsymbol{p}$ due to a point vortex singularity at point $s$ is:

$$
\boldsymbol{u}_{\text {vortex }}(\boldsymbol{p}, \boldsymbol{s})=\Gamma \cdot\left(\begin{array}{c}
\frac{\sin \theta}{2 \cdot \pi \cdot|\boldsymbol{p}-\boldsymbol{s}|} \\
\frac{-\cos \theta}{2 \cdot \pi \cdot|\boldsymbol{p}-\boldsymbol{s}|}
\end{array}\right)
$$

where $\Gamma$ is the vortex strength. Imposing the boundary conditions, so the induced speed due to all the singularities is tangential to the last computed flow at the stator inlet and to the stator blades at the three-quarter-chord point of a blade, the problem becomes:

$$
\boldsymbol{A I C} \cdot\left(\begin{array}{c}
\Gamma_{b l} \\
\Gamma_{\text {origin }}
\end{array}\right)=-\left[\begin{array}{c}
\boldsymbol{u}_{\text {sink }}\left(p_{b l, b c}, \boldsymbol{o}\right) \cdot \boldsymbol{n}_{b l, b c} \\
\boldsymbol{u}_{\text {sink }}\left(p_{s t, i n, b c}, \boldsymbol{o}\right) \cdot \boldsymbol{n}_{s t, i n, b c}
\end{array}\right]
$$

where $\boldsymbol{A I C}$ is the matrix of aerodynamic influence coefficients, $\Gamma_{b l}$ is the vortex strength of the stator blades, $\Gamma_{\text {origin }}$ is the vortex strength of the origin, $\boldsymbol{p}_{b l, b c}$ is the three-quarter-chord point of one of the blades, $\boldsymbol{n}_{b l, b c}$ is the normal vector to the blade chord at that point, $\boldsymbol{o}$ is the point at the origin of the stator reference frame, $\boldsymbol{p}_{s t, i n, b c}$ is the point at the stator inlet where the flow speed angle at the last time-step is known and $\boldsymbol{n}_{s t, i n, b c}$ is the normal vector to that flow speed. $\boldsymbol{A I C}$ is computed as follows:

$$
\begin{aligned}
\boldsymbol{A I C}_{1,1} & =\sum \boldsymbol{u}_{\text {vortex }}\left(\boldsymbol{p}_{b l, b c}, \boldsymbol{p}_{b l, q c}\right) \cdot \boldsymbol{n}_{b l, b c} \\
\boldsymbol{A I C}_{1,2} & =\boldsymbol{u}_{\text {vortex }}\left(\boldsymbol{p}_{b l, b c}, \boldsymbol{o}\right) \cdot \boldsymbol{n}_{b l, b c} \\
\boldsymbol{A} \boldsymbol{I} \boldsymbol{C}_{2,1} & =\sum \boldsymbol{u}_{\text {vortex }}\left(\boldsymbol{p}_{s t, i n, b c}, \boldsymbol{p}_{b l, q c}\right) \cdot \boldsymbol{n}_{s t, i n, b c} \\
\boldsymbol{A} \boldsymbol{I} \boldsymbol{C}_{2,2} & =\boldsymbol{u}_{\text {vortex }}\left(\boldsymbol{p}_{s t, i n, b c}, \boldsymbol{o}\right) \cdot \boldsymbol{n}_{s t, i n, b c}
\end{aligned}
$$

where $\boldsymbol{p}_{b l, q c}$ is the blade quarter-chord point where the vortex is located. $\boldsymbol{A} \boldsymbol{I} \boldsymbol{C}_{1,1}$ and $\boldsymbol{A} \boldsymbol{I} \boldsymbol{C}_{2,1}$ are computing using a summatory for all the blades quarter-chord points. As seen in Equation A.20, the second row of $\boldsymbol{A I C}$ has to be computed only if there is a change in the geometry of the stator (i.e., the blades are rotated) and the first row only depends of the inlet flow angle for a given position of the blades, so memoisation techniques has been applied in order to minimise even more the computational cost of computing the stator outlet flow angle. After solving Equation A.19 and obtaining the strength of the vortexes, the induced speed is computed at a point in the stator outlet: $\alpha_{3}$ is taken as the angle of this induced speed.

\section{Appendix A.3. Rotor flow}

The rotor outlet speed is computed assuming a constant rothalpy evolution. This way, the rotor outlet relative speed $w_{4}$ becomes:

$$
\begin{gathered}
T_{3 t, r e l}-\frac{\left(\omega \cdot r_{r t, \text { in }}\right)^{2}}{2 \cdot c_{p}}=T_{4}-\frac{\left(\omega \cdot \bar{r}_{r t, \text { out }}\right)^{2}-w_{4}^{2}}{2 \cdot c_{p}} \\
w_{4}=\left[2 \cdot c_{p} \cdot\left(T_{3 t, r e l}-T_{4}\right)\right. \\
\left.-\omega^{2} \cdot\left(r_{r t, \text { in }}^{2}-\bar{r}_{r t, \text { out }}^{2}\right)\right]^{\frac{1}{2}} \\
w_{4}=\left\{\begin{array}{c}
\gamma \cdot \frac{\gamma}{\gamma-1} \cdot R \cdot T_{3 t, \text { rel }} \cdot\left[1-\left(\frac{p_{3 t, r e l}}{p_{4}}\right)^{\frac{1-n_{r t}}{n_{r t}}}\right. \\
\left.-\omega^{2} \cdot\left(r_{r t, \text { in }}^{2}-\bar{r}_{r t, \text { out }}^{2}\right)\right\}^{\frac{1}{2}}
\end{array}\right.
\end{gathered}
$$

where $\omega$ is the rotational speed of the rotor, $r_{r t, i n}$ is the rotor inlet radius and $\bar{r}_{r t, \text { out }}$ is the rotor outlet mean radius. The relative pressure and temperature $p_{3 t, \text { rel }}$ and $T_{3 t \text {,rel }}$ are computed as follows:

$$
\begin{gathered}
T_{3 t, r e l}=T_{3}+\frac{w_{3}^{2}}{2 \cdot c_{p}} \\
p_{3 t, r e l}=p_{3 t} \cdot\left(\frac{T_{3 t, r e l}}{T_{3 t}}\right)^{\frac{\gamma-1}{\gamma}}
\end{gathered}
$$

The rotor inlet pressure and temperature are that of the stator cell and the outlet pressure is the pressure of the first cell of the turbine outlet.

The rotor inlet relative speed $w_{3}$ is computed as: 


$$
\begin{aligned}
w_{3, r} & =u_{s t} \cdot \sin \alpha_{3} \\
w_{3, \tau} & =u_{s t} \cdot \cos \alpha_{3}-\omega \cdot r_{r t, i n} \\
w_{3} & =\sqrt{w_{3, r}^{2}+w_{3, \tau}^{2}}
\end{aligned}
$$

where $w_{3, r}$ is the radial rotor inlet relative speed and $w_{3, \tau}$ is the tangential rotor inlet relative speed. A schematic drawing of the rotor inlet is shown in Figure A.14, while the rotor outlet is shown in Figure A.15.

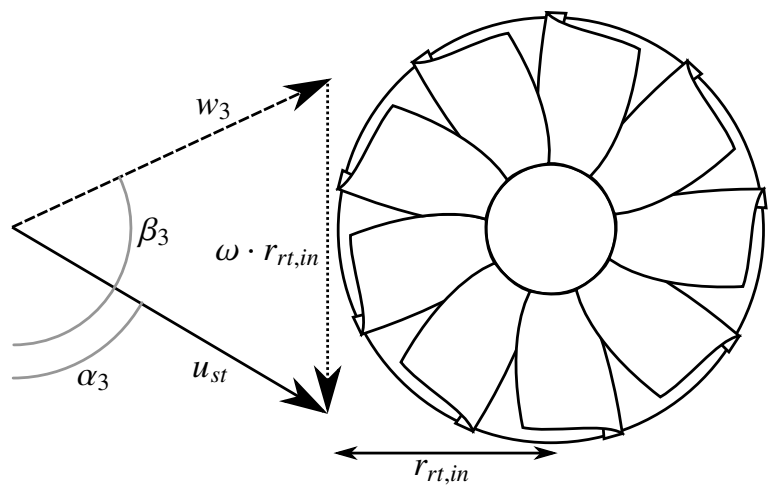

Figure A.14: Rotor inlet velocity scheme.

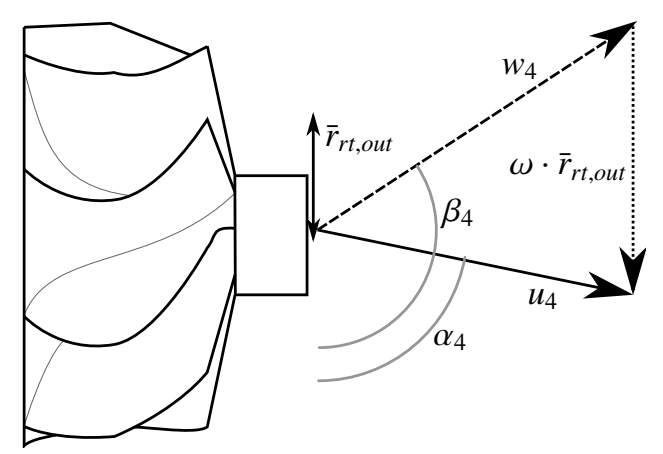

Figure A.15: Rotor outlet velocity scheme.

To compute the rotor mass flow rate, the rotor outlet density is needed:

$$
\begin{aligned}
\rho_{4} & =\frac{p_{4}}{R \cdot T_{4}}=\frac{p_{4}}{p_{3 t, r e l}} \cdot \frac{T_{3 t, r e l}}{T_{4}} \cdot \frac{p_{3 t, r e l}}{R \cdot T_{3 t, r e l}} \\
& =\frac{p_{3 t, r e l}}{R \cdot T_{3 t, r e l}} \cdot\left(\frac{p_{3 t, r e l}}{p_{4}}\right)^{-\frac{1}{n_{r t}}}
\end{aligned}
$$

Thus, the rotor outlet mass flow rate becomes:

$$
\left.\frac{\mathrm{d} m}{\mathrm{~d} t}\right|_{r t}=\frac{p_{3 t, r e l}}{R \cdot T_{3 t, r e l}} \cdot\left(\frac{p_{3 t, r e l}}{p_{4}}\right)^{-\frac{1}{n_{r t}}} \cdot A_{4} \cdot \sin \beta_{4} \cdot w_{4}
$$

The rotor outlet total temperature is:

$$
\begin{aligned}
T_{4 t}= & T_{3 t, r e l} \cdot\left(\frac{p_{3, r e l}}{p_{4}}\right)^{\frac{n_{r t}-1}{n_{r t}}}+\frac{\left(w_{4} \cdot \sin \beta_{4}\right)^{2}}{2 \cdot c_{p}} \\
& +\frac{\left(w_{4} \cdot \cos \beta_{4}+\omega \cdot \bar{r}_{r t, \text { out }}\right)^{2}}{2 \cdot c_{p}}
\end{aligned}
$$

As in the case of the stator, the polytropic coefficient can be computed using losses models that dissipate stagnation pressure from the rotor inlet conditions to a virtual state after which a constant-entropy evolution is done.

In this case, several losses models are used to compute $\Delta p_{r t, l o s s}$. The first implemented model is due to Futral and Wasserbauer [30], and it is commonly known as the NASA model. This model can be implemented by a first virtual kinetic energy loss equivalent to the kinetic energy of the tangential component of the rotor inlet flow followed by an isobaric process to recover the rotor inlet total relative temperature:

$$
\frac{\Delta p_{r t, l o s s, N A S A}}{p_{3 t, r e l}}=1-\left[\frac{T_{3 t, r e l}-\frac{w_{3}^{2} \cdot \sin \left(\beta_{3, o p t}-\beta_{3}\right)^{2}}{2 \cdot c_{p}}}{T_{3 t, r e l}}\right]^{\frac{\gamma}{\gamma-1}}
$$

where $\beta_{3}$ is the stator outlet flow angle in relative coordinates and $\beta_{3, o p t}$ is the rotor inlet optimum angle. At the rotor inlet optimum angle the flow experiences no losses due to the NASA shock losses model.

The second losses model is due to Wasserbauer and Glassman [31], and it is computed as a stagnation pressure loss proportional to the dynamic pressure at the rotor outlet plus the radial component of the rotor inlet dynamic pressure:

$$
\Delta p_{r t, l o s s, p s g}=\frac{K_{\text {loss }, p s g}}{2} \cdot\left(\rho_{3} \cdot w_{3, r}^{2}+\rho_{4} \cdot w_{4}^{2}\right)
$$

where $K_{\text {loss,psg }}$ is a constant for a given turbine. The last timestep rotor outlet relative velocity can be used to reduce computational costs. Thus, the total pressure loss becomes:

$$
\Delta p_{r t, l o s s}=\Delta p_{r t, l o s s, N A S A}+\Delta p_{r t, l o s s, p s g}
$$

Although tip clearance losses due to recirculation affect the rotor efficiency as can be seen in some recent works such as Huang's thesis [32], the U-RANS simulations used to calibrate the model lacked such effects, so no tip clearance losses model has been implemented.

Finally, if the rotor pressure ratio is high enough, the flow becomes sonic in the rotor throat. The rotor outlet pressure that produces critic conditions can be computed similarly to that of the stator, as seen in Equation A.13.

$$
p_{4, c h}=\left[\frac{2 \cdot c_{p} \cdot T_{3 t, r e l}-\omega^{2}\left(r_{r t, \text { in }}^{2}-\bar{r}_{r t, \text { out }}^{2}\right)}{\left(1+\frac{2}{\gamma-1}\right) \cdot \gamma \cdot R \cdot T_{3 t, r e l}}\right]^{\frac{n_{r t}}{n_{r t}-1}}
$$


At each time-step, $p_{4, c h}$ is computed: if the rotor outlet pressure is less than it, the mass flow rate is computed as if $p_{4}=p_{4, c h}$ and the final outlet speed is computed so the gas law is obeyed and the rotor outlet total temperature is equal to that of the rotor throat.

\section{Acknowledgements}

The authors are indebted to the Spanish Ministerio de Economía y Competitividad through Project TRA 2010-16205.

The authors also wish to thank Mr. Roberto Navarro for his invaluable work during CFD simulations.

\section{Nomenclature}

a Speed of sound

B.C. Boundary condition

CFD Computational Fluid Dynamics

$c_{v} \quad$ Specific heat capacity at constant volume

$c_{p} \quad$ Specific heat capacity at constant pressure

$e \quad$ Specific internal energy

$h \quad$ Specific enthalpy

ICE Internal combustion engine

$n \quad$ Polytropic coefficient

$p \quad$ Pressure

$R \quad$ Gas constant

$r \quad$ Radius

$s \quad$ Specific entropy

$T \quad$ Temperature

$t \quad$ Time

$u \quad$ Speed

V Volume

$\dot{W} \quad$ Power

$x \quad$ Length, position

$y$ Height

Vectors and matrices

AIC Aerodynamic influence coefficients matrix

C Source terms vector

$\boldsymbol{F} \quad$ Flow terms vector

$\boldsymbol{n}$ Unitary normal vector

$\boldsymbol{o} \quad$ Stator reference frame origin

$\boldsymbol{p} \quad$ Point position

$s \quad$ Point position

$\boldsymbol{w} \quad$ State vector

Subscripts

bc Boundary condition

$\begin{array}{ll}\text { bl } & \text { Blade } \\ c h & \text { Choked, critic flow } \\ i & \text { Cell number } \\ \text { in } & \text { Inlet } \\ \text { loss } & \text { Losses } \\ \text { NAS A } & \text { NASA losses model } \\ o & \text { Origin } \\ \text { opt } & \text { Optimum } \\ \text { out } & \text { Outlet } \\ p s g & \text { Passage losses model } \\ r e f & \text { Refference quantity } \\ r e l & \text { Relative } \\ r t & \text { Rotor } \\ \text { sink } & \text { Sink singularity } \\ \text { st } & \text { Stator } \\ t & \text { Total or stagnation conditions } \\ \text { vortex } & \text { Vortex singularity } \\ w & \text { Volute window } \\ 0 & \text { Domain inlet } \\ 1 & \text { Turbine inlet } \\ 2 & \text { Stator inlet } \\ 3 & \text { Stator outlet } \\ 4 & \text { Rotor outlet } \\ 5 & \text { Turbine outlet } \\ 6 & \text { Domain outlet } \\ & \end{array}$

Greek letters

$\begin{array}{lll}\alpha & \text { Absolute flow angle } & \mathrm{rad} \\ \beta & \text { Relative flow angle } & \mathrm{rad} \\ \Delta & \text { Difference, step, length } & \\ \Gamma & \text { Vortex strength } & \mathrm{m} \mathrm{s}^{2} \\ \gamma & \text { Specific heat capacities ratio } & \\ \lambda & \text { Pressure propagation speed } & \mathrm{m} \mathrm{s}^{-1} \\ \omega & \text { Rotational speed } & \mathrm{rad} \mathrm{s}^{-1} \\ \tau & \text { Tangential component } & \\ \rho & \text { Density } & \mathrm{kg} \mathrm{m}^{-3} \\ \theta & \text { Angle } & \mathrm{rad}\end{array}$

Overbar

- Mean value

Time-derivative

* Corrected value

\section{References}

[1] Romagnoli A, Martinez-Botas R. Performance prediction of a nozzled and nozzleless mixed-flow turbine in steady conditions. International Journal of Mechanical Sciences 2011;53(8):557 -74. URL: http://www.sciencedirect.com/science/article/ pii/S0020740311000920.

[2] Payri F, Serrano JR, Fajardo P, Reyes-Belmonte MA, Gozalbo-Belles R. A physically based methodology to extrapolate performance maps of radial turbines. Energy Conversion and Management 2012;55(0):149 -63. URL: http://www.sciencedirect.com/science/article/ pii/S0196890411003104.

[3] Bohn D, Moritz N, Wolff M. Conjugate flow and heat transfer investigation of a turbo charger: Part ii — experimental results. ASME Conference Proceedings 2003;2003(3686):723-9. URL: http://link.aip. org/link/abstract/ASMECP/v2003/i3686X/p723/s1. 
[4] Serrano JR, Olmeda P, Páez A, Vidal F. An experimental procedure to determine heat transfer properties of turbochargers. Measurement Science and Technology 2010;21(3):035109. URL: http://stacks.iop.org/ $0957-0233 / 21 / i=3 / a=035109$.

[5] Olmeda P, Dolz V, Arnau FJ, Reyes-Belmonte MA. Determination of heat flows inside turbochargers by means of a one dimensional lumped model. Mathematical and Computer Modelling 2013;57(78):1847 52. URL: http://www.sciencedirect.com/science/article/ pii/S0895717711007631.

[6] Serrano JR, Olmeda P, Arnau FJ, Reyes-Belmonte MA, Lefebvre A. Importance of heat transfer phenomena in small turbochargers for passenger car applications. SAE Int J Engines 2013;6(2):716 -28.

[7] Serrano JR, Olmeda P, Tiseira A, García-Cuevas LM, Lefebvre A. Theoretical and experimental study of mechanical losses in automotive turbochargers. Energy 2013;55(0):888 -98. URL: http://www.sciencedirect.com/science/article/pii/ S0360544213003538.

[8] Serrano JR, Olmeda P, Tiseira A, García-Cuevas LM, Lefebvre A. Importance of mechanical losses modeling in the performance prediction of radial turbochargers under pulsating flow conditions. SAE Int J Engines 2013;6(2):729 -38.

[9] Copeland CD, Martínez-Botas RF, Seiler M. Comparison between steady and unsteady double-entry turbine performance using the quasi-steady assumption. Journal of Turbomachinery: Transactions of the ASME 2010;133.

[10] Galindo J, Fajardo P, Navarro R, García-Cuevas LM. Characterization of a radial turbocharger turbine in pulsating flow by means of CFD and its application to engine modeling. Applied Energy 2013;103(0):116 -27. URL: http://www.sciencedirect.com/science/article/ pii/S0306261912006538.

[11] Hakeem I, Su CC, Costall A, Martínez-Botas RF. Effect of volute geometry on the steady and unsteady performance of mixed-flow turbines. In: Proceedings of the Institution of Mechanical Engineers Part A-Journal of Power and Energy; vol. 221. 2007, p. 535-50.

[12] Abdelmadjid C, Mohamed SA, Boussad B. CFD analysis of the volute geometry effect on the turbulent air flow through the turbocharger compressor. Energy Procedia 2013;36(0):746 55. URL: http://www.sciencedirect.com/science/article/ pii/S1876610213011739; terraGreen 13 International Conference 2013 - Advancements in Renewable Energy and Clean Environment.

[13] Chen H, Hakeem I, Martínez-Botas RF. Modelling of a turbocharger turbine under pulsating inlet conditions. In: Proceedings of the Institution of Mechanical Engineers, Part A: Journal of Power and Energy. Institution of Mechanical Engineers; 1996, p. 397-408.

[14] Chiong MS, Rajoo S, Romagnoli A, Martínez-Botas RF. Single entry mixef flow turbine performance prediction with 1-d gas dynamic code coupled with mean line model. International Journal of Gas Turbine, Propulsion and Power Systems 2012;4(2):8-16.

[15] Macek J, Vitek O, Zak Z. Calibration and results of a radial turbine 1d model with distributed parameters. Tech. Rep. SAE Technical Paper 2011-01-1146; SAE International; 2011.

[16] Baines N. Turbocharger turbine pulse flow performance and modelling - 25 years on. In: 9th International Conference on Turbochargers and Turbocharging. 2010, p. 347-62.

[17] Serrano JR, Arnau FJ, Dolz V, Tiseira A, Cervelló C. A model of turbocharger radial turbines appropriate to be used in zero- and onedimensional gas dynamics codes for internal combustion engines modelling. Energy Conversion and Management 2008;49:3729-45.

[18] Serrano JR, Arnau FJ, Fajardo P, Reyes-Belmonte MA. Contribution to the modeling and understanding of cold pulsating flow influence in the efficiency of small radial turbines for turbochargers. Journal of Engineering for Gas Turbines and Power 2012;134(10).

[19] Du J, Wang Y, Yang C, Wang H. Hardware-in-the-loop simulation approach to testing controller of sequential turbocharging system. In: Proceedings of the IEEE Conference on Automation and Logistics. IEEE; 2007, p. 2426-31.

[20] Cheng X, Liang X. Discussion on the applicability of entropy generation minimization to the analyses and optimizations of thermodynamic processes. Energy Conversion and Management 2013;73(0):121 -7. URL: http://www.sciencedirect.com/ science/article/pii/S0196890413002094. doi:http://dx.doi. org/10.1016/j.enconman.2013.04.012.

[21] van Leer B. Towards the ultimate conservative difference scheme, V. A second order sequel to Godunov's method. Journal of Computational Physics 1979;32:101-36.

[22] Einfeld B. On godunov-type methods for gas dynamics. SIAM J Numer Anal 1988;25(2):294-318. URL: http://dx.doi.org/10.1137/ 0725021

[23] Toro E, Spruce M, Speares W. Restoration of the contact surface in the hll-riemann solver. Shock Waves 1994;4(1):25-34. URL: http://dx. doi.org/10.1007/BF01414629.

[24] Bozza F, De Bellis V, Marelli S, Capobianco M. 1d simulation and experimental analysis of a turbocharger compressor for automotive engines under unsteady flow conditions. SAE International Journal of Engines 2011;4(1):1365-84.

[25] Moustapha H, Zelesky MF, Baines NC, Japikse D. Axial and Radial Turbines. 2003.

[26] Galindo J, Hoyas S, Fajardo P, Navarro R. Set-up analysis and optimization of CFD simulations for radial turbines. Engineering Applications of Computational Fluid Mechanics 2013;7(4):441-60.

[27] Godunov SK. A difference scheme for numerical solution of discontinuous solution of hydrodynamic equations. Matematicheskii Sbornik 1959;47:271-306.

[28] Courant R, Friedrichs K, Lewy H. Über die partiellen differenzengleichungen der mathematischen physik. Mathematische Annalen 1928;100(1):32-74. URL: http://dx.doi.org/10.1007/ bf 01448839 .

[29] Katz J, Plotkin A. Low-Speed Aerodynamics. 2nd ed.; Cambridge University Press; 2001. URL: http://books .google.fr/books?id= rAS1DmBRLo8C.

[30] Futral S, Wasserbauer C, Aeronautics USN, Administration S. Off-design performance prediction with experimental verification for a radial-inflow turbine: Samuel m.futral jr. and charles a. wasserbauer. Tech. Rep. NASA TN D-2621; NASA; 1965. URL: http://books.google.es/books? id $=\mathrm{N} 1 \mathrm{kzLAHfK}-\mathrm{IC}$

[31] Wasserbauer CA, J. GA. Fortran program for predicting the off-design performance of radial inflow turbines. Tech. Rep. NASA TN-8063; NASA; 1975

[32] Huang A. Loss mechanisms in turbine tip clearance flows. 2011. 